This peer-reviewed published paper appears as: Kolwankar, S., Kanvinde, A., Kenawy, M., Lignos, D.G., Kunnath, S. (2018). "Simulating Local Buckling-Induced Softening in Steel Members Using an Equivalent Nonlocal Material Model in Displacement-Based Fiber Elements, ASCE

Journal of Structural Engineering, Vol. 144(10): 04018192-1, doi: 10.1061/(ASCE)ST.1943-541X.0002189

\title{
Simulating Local Buckling-INDUCed SofTening in STEel Members Using AN Equivalent Nonlocal MATerial MOdel in DiSPlacement-BaSed Fiber Elements
}

\section{Subodh Kolwankar ${ }^{1}$, Amit Kanvinde ${ }^{2}$, Member, Maha Kenawy ${ }^{3}$, Dimitrios Lignos ${ }^{4}$, Member, and Sashi Kunnath ${ }^{5}$, Fellow}

\section{Abstract}

Fiber-based elements are commonly used to simulate steel beam-columns, due to their ability to capture P-M interactions and spread-of-plasticity. However, when mechanisms such as local buckling result in effective softening at the fiber-scale, conventional fiber models exhibit mesh dependence. To address this, a two-dimensional nonlocal fiber-based beam-column model is developed and implemented numerically. The model focuses on hot-rolled wide flange (W-) sections that exhibit local buckling- induced softening when subjected to combinations of axial compression and flexure. The formulation up-scales a previously developed nonlocal formulation for "single-fiber" buckling to the full frame element. The formulation incorporates a physical length scale associated with local buckling, along with an effective softening constitutive relationship at the fiber level. To support these aspects of the model, 43 Continuum Finite Element (CFE) test-problems are constructed. These test-problems examine a range of parameters including the axial load, cross-section, and moment gradient. The implemented formulation is validated against CFE models as well as physical steel beam-column experiments that exhibit local bucklinginduced softening. The formulation successfully predicts post-peak response for these validation cases in a mesh-independent manner, while also capturing the effects of P-M interactions and moment gradient. To enable convenient generalization, guidelines for calibration and selection of the model parameters are provided. Limitations are discussed along with areas for future development.

KEYWORDS: Fiber models; localization; nonlocal formulations; frame elements

\footnotetext{
${ }^{1}$ Graduate Research Assistant, Department of Civil and Environmental Engineering, University of California, Davis, CA, 95616, USA.

${ }^{2}$ Professor, Department of Civil and Environmental Engineering, University of California, Davis, CA, 95616, USA. Corresponding author

${ }^{3}$ Graduate Research Assistant, Department of Civil and Environmental Engineering, University of California, Davis, CA, 95616, USA.

${ }^{4}$ Associate Professor, Department of Architecture, Civil and Enviromental Engineering, Ecole Polytechnique Fédérale de Lausanne (EPFL), Lausanne, 1015, CH.

${ }^{5}$ Professor, Department of Civil and Environmental Engineering, University of California, Davis, CA, 95616, USA.
} 
This peer-reviewed published paper appears as: Kolwankar, S., Kanvinde, A., Kenawy, M., Lignos, D.G., Kunnath, S. (2018). "Simulating Local Buckling-Induced Softening in Steel Members Using an Equivalent Nonlocal Material Model in Displacement-Based Fiber Elements, ASCE Journal of Structural Engineering, Vol. 144(10): 04018192-1, doi: 10.1061/(ASCE)ST.1943-541X.0002189

\section{INTRODUCTION}

27 Extreme limit states, such as earthquake- or blast-induced collapse in steel framed structures are precipitated by loss in component strength at high deformations. In rolled-steel beam-columns,

29 local buckling is often the mechanism responsible for strength loss (others being lateral-torsional buckling and fracture). Figure 1 schematically shows a rolled-steel beam-column subjected to flexure, illustrating flange local buckling within the plastic hinge region. As indicated in the figure, strongly geometric nonlinear response within the buckling zone results in negative stiffness at the component level (Hamburger et al., 2009). While loss of component strength is one outcome of this negative stiffness, localization of deformation in the buckling zone is another. Localization of deformation ultimately leads to fracture through plastic strain amplification. Research indicates that simulating this "post-peak" response is critical for accurate structural performance assessment.

37 For example, Ibarra and Krawinkler (2005) show that the post-peak negative stiffness is a dominant parameter controlling seismic collapse of steel framed structures, whereas Fell et al., (2010) indicate that the continuum plastic strain within the local buckle triggers ductile fracture in steel braces. Post-local buckling response can be simulated accurately through large-deformation

41 elastoplastic Continuum Finite Element (CFE) simulations, in which material response is 42 represented as monotonically hardening, supplemented by direct simulation of geometric 43 nonlinear effects that give rise to the negative stiffness (see e.g., Fogarty and El-Tawil, 2015;

44 Elkady and Lignos, 2015). However, line-element based models using beam-column frame 45 elements remain a popular choice for structural performance assessment in most practical, and 46 even research settings. This is attributed to their computational efficiency, which (despite rapid 47 advances in computing hardware) is increasing in importance as emerging trends in structural 
This peer-reviewed published paper appears as: Kolwankar, S., Kanvinde, A., Kenawy, M., Lignos, D.G., Kunnath, S. (2018). "Simulating Local Buckling-Induced Softening in Steel Members Using an Equivalent Nonlocal Material Model in Displacement-Based Fiber Elements, ASCE Journal of Structural Engineering, Vol. 144(10): 04018192-1, doi: 10.1061/(ASCE)ST.1943-541X.0002189

performance and reliability assessment (FEMA P-58, 2012; NIST, 2010) mandate computationally onerous suites of parametric simulations.

Despite their computational efficiency, line-elements have significant limitations, especially when

51 simulating post-peak response. To describe these, it is useful to classify line-element based

52 approaches as either as concentrated plasticity or plastic hinge elements (refer Dides and de la

53 Llera, 2005, for a comprehensive review), or distributed-plasticity elements (Spacone and

54 Filippou, 1996). Distributed-plasticity elements may be further classified as force-based vs.

55 displacement-based. Fiber elements are a specific instance of distributed plasticity elements, in

56 which stress resultants and deformations are determined at the cross-sectional (rather than

57 continuum) level. Plastic hinge models require calibration to component tests (i.e., cannot be

58 conveniently generalized from material tests), do not simulate spread of plasticity, and require $a$ priori placement of plastic hinges, disallowing simulation of yielding in arbitrary locations. Moreover, although theoretically possible, concentrated plasticity models do not typically capture axial force-moment $(P-M)$ interaction. The latter (i.e., fiber elements) rely on uniaxial stressstrain response at a fiber cross-sectional level, enabling simulation of plasticity in arbitrary

63 locations, spread-of-plasticity, $P-M$ interaction, and perhaps most importantly, generalization of properties from material (rather than component) tests. However, for simulating post-peak response, fiber elements are susceptible to problems when softening constitutive models are used to represent post-buckling response. Specifically, post-peak response (both negative stiffness and

67 curvature distribution) predicted by fiber-elements is susceptible to severe mesh-dependence or non-objectivity (Coleman and Spacone, 2001; Wu and Wang, 2010, Sideris and Salehi, 2016). It is relevant to note here that such mesh-dependence is not a peculiarity of fiber elements, but occurs even in CFE simulations when softening constitutive models are used. Nonetheless, unlike fiber- 
This peer-reviewed published paper appears as: Kolwankar, S., Kanvinde, A., Kenawy, M., Lignos, D.G., Kunnath, S. (2018). "Simulating Local Buckling-Induced Softening in Steel Members Using an Equivalent Nonlocal Material Model in Displacement-Based Fiber Elements, ASCE Journal of Structural Engineering, Vol. 144(10): 04018192-1, doi: 10.1061/(ASCE)ST.1943-541X.0002189

71 models, CFE models offer a convenient way to simulate post-buckling response without the use

72 of softening constitutive laws. The implication is that such non-objectivity is usually more difficult

to overcome in fiber models. Figure 1 illustrates this non-objectivity, wherein the negative stiffness in any element (or mesh unit such as Gauss point spacing commonly used in fiber elements) localizes strains in that unit, unloading the neighboring intervals. Thus, the Gauss point spacing (or mesh size) acts as an arbitrary length scale, controlling the strain distribution and global loaddeformation response. This type of mesh-dependence due to softening is a well-studied phenomenon (Engelen et al., 2003; Jirásek and Rolshoven, 2003; Bazant and Jirásek, 2002) in the context of material softening in CFE simulations. This mesh-dependence arises from the singular nature of the analytical solution when softening constitutive models are used without an accompanying physical length scale; the solution converges to this singular solution as the mesh is refined. Introducing a physical "regularizing" length scale into the simulation (if done appropriately) has the potential to mitigate this mesh dependence, by distributing strains over a region defined by this length scale. Analogous research for fiber-based frame elements is not as extensive (examples include Pugh et al., 2015; Valipour and Foster, 2009; Salehi and Sideris, 2017; Zhang and Khandelwal, 2016; Khaloo and Tariverdilo, 2002, 2003). As a consequence, popular commercial (e.g., PERFORM-3D, ETABS; Computers and Structures, 2016) and research codes (e.g., OpenSees, McKenna et al., 2012) still utilize fiber-elements that are not regularized in any manner, and suffer from pathological mesh dependence. For frame elements, the regularizing length-scale may be introduced by coordinating the mesh size with the softening/negative slope of the constitutive model to produce acceptable load-deformation response. As an example, Coleman and Spacone (2001) used the fracture energy to regularize the constitutive law, based on concepts developed by Bazant and Oh (1983) and Bazant and Planas (1998). Although this approach 
This peer-reviewed published paper appears as: Kolwankar, S., Kanvinde, A., Kenawy, M., Lignos, D.G., Kunnath, S. (2018). "Simulating Local Buckling-Induced Softening in Steel Members Using an Equivalent Nonlocal Material Model in Displacement-Based Fiber Elements, ASCE Journal of Structural Engineering, Vol. 144(10): 04018192-1, doi: 10.1061/(ASCE)ST.1943-541X.0002189

expediently mitigates mesh dependency in load-deformation response, it still generates localized strain and curvature distributions. On the other hand, "nonlocal" formulations enrich the strains by explicitly introducing a length scale (examples include Salehi and Sideris, 2017; Zhang and Khandelwal, 2016), wherein the nonlocal strain at any location is computed from strains at neighboring locations as a weighted average. In continuum modeling, the use of nonlocal approaches and the inclusion of a material-dependent length scale is well-established. Examples include the simulation of material damage or deterioration (e.g., crushing in concrete - di Prisco and Mazars, 1996, or shear banding in geo-materials - Shuttle and Smith, 1988); correspondingly, the length scales reflect material morphological features and heterogeneities that are otherwise not simulated in continuum models (such as aggregate size in concrete - Bazant, 1976). In contrast, softening and localization (at the component scale) in rolled steel members is often triggered by three-dimensional geometric nonlinear phenomena such as local buckling, for which length scales have physical basis in these phenomena (such as the buckle wavelength - see Figure 1). Other sources of component-scale softening in steel members include global buckling, lateral-torsional buckling, or ductile tearing. Common approaches for the simulation of local buckling (which is the focus of this paper) within fiber elements include the following (1) simulating the softening in a local constitutive manner, disregarding mesh sensitivity entirely, with serious loss of accuracy and objectivity at extreme limit states, (2) using approaches for mesh adjustment outlined above, which also result in localized strains and curvatures, or (3) concentrated plastic hinge formulations, which mitigate non-objectivity but are deficient in other ways, i.e., they cannot simulate plasticity at arbitrary locations or distributed plasticity, are not facile with respect to the simulation of $P$ $M$ interaction, and require component (rather than material) tests for calibration. 
This peer-reviewed published paper appears as: Kolwankar, S., Kanvinde, A., Kenawy, M., Lignos, D.G., Kunnath, S. (2018). "Simulating Local Buckling-Induced Softening in Steel Members Using an Equivalent Nonlocal Material Model in Displacement-Based Fiber Elements, ASCE Journal of Structural Engineering, Vol. 144(10): 04018192-1, doi: 10.1061/(ASCE)ST.1943-541X.0002189

116 Recent work by the authors (Kolwankar et al., 2017) demonstrated that an integral-based nonlocal

117 formulation is able to successfully mitigate buckling-induced mesh dependence in a steel bar

118 represented as a single fiber, while also reproducing the strain distribution within the localized

119 (buckled) zone. This is promising vis-à-vis the above discussion, because this single-fiber

120 formulation provides a basis for extension to a full fiber-based beam-column element. Motivated

121 by this, the specific objectives of this paper are: (1) to present a 2-d fiber beam-column element

122 formulation to simulate rolled steel W-sections subjected to monotonic flexural/axial load, that

123 uses a nonlocal approach to mitigate mesh dependence of post-peak response, (2) to present a

124

125

126

127

128

129

130

131

132

133

134

135

136

137

138

method for determining the characteristic length corresponding to local buckling as an input to the nonlocal approach, (3) to describe the numerical implementation of the model with guidelines for calibration and usage, and (4) to evaluate this implemented formulation against CFE as well as test data. The paper begins by articulating the scope of the problem, and the scientific methodology. Subsequent sections describe individual components of this methodology; these include the nonlocal formulation itself, and characterization of its various aspects including length scales and softening constitutive response, using CFE simulations. This is followed by a brief discussion of the numerical implementation within OpenSees, and validation of the approach against CFE simulations as well as physical experiments. The paper concludes by providing guidelines for usage, and discusses limitations of the approach and its implementation.

\section{METHODOLOGY AND COMPONENTS OF RESEARCH}

Figure 2 schematically illustrates the main components of the research methodology. Referring to the figure, the target application is rolled-steel beam-columns (e.g., in moment resisting frames) 
This peer-reviewed published paper appears as: Kolwankar, S., Kanvinde, A., Kenawy, M., Lignos, D.G., Kunnath, S. (2018). "Simulating Local Buckling-Induced Softening in Steel Members Using an Equivalent Nonlocal Material Model in Displacement-Based Fiber Elements, ASCE Journal of Structural Engineering, Vol. 144(10): 04018192-1, doi: 10.1061/(ASCE)ST.1943-541X.0002189

subjected to inelastic bending coupled with axial force demands. Given this, a suite of 43 test problems was developed. Each of these is a cantilever column with properties and loading conditions summarized in Table 1; of these, simulations \#41-43 are complementary to columns physically tested by Lignos et al., (2016). In addition to its geometric simplicity and determinacy, the cantilever column enables effective interrogation of four key variables that are critical from the perspective of moment frame simulation: the cross-sectional shape, axial load ratio (expressed as $P / P_{y}$ - the fraction of the yield strength), moment gradient (denoted as the moment-shear ratio $M / V$ ), and manner of loading, i.e., non-proportional - with the axial load introduced prior to lateral deformation, or proportional - wherein both loads are introduced simultaneously. The values of these parameters (also summarized in Table 1), and the cantilever lengths of the column $(L=M / V$, defining the moment gradient) were selected to encompass commonly occurring conditions in seismic design and response (Elkady and Lignos, 2015). For each test problem, two simulation models (both illustrated schematically in Figure 2) were constructed:

- A Continuum Finite Element (CFE) model in the commercial platform ABAQUS (2013): Validated against experimental data by Lignos et al., (2016), this model provides qualitative and quantitative insights into the modes of local buckling, to inform the nonlocal formulation for the line element model. This includes buckling shapes, deformation and strain patterns, localization length and its variation over the cross-section, and effective stress-strain response of the buckling portions of the cross-section. Additionally, the CFE models provide a calibration and validation dataset for the line-element model.

- A nonlocal strain-enabled fiber-based line element model in the platform OpenSees (2012):

60 Referring to Figure 2, this model (abbreviated henceforth as NFE - Nonlocal Fiber Element) consists of $n$ displacement-based beam-column elements (with cubic shape functions) 
This peer-reviewed published paper appears as: Kolwankar, S., Kanvinde, A., Kenawy, M., Lignos, D.G., Kunnath, S. (2018). "Simulating Local Buckling-Induced Softening in Steel Members Using an Equivalent Nonlocal Material Model in Displacement-Based Fiber Elements, ASCE

Journal of Structural Engineering, Vol. 144(10): 04018192-1, doi: 10.1061/(ASCE)ST.1943-541X.0002189 connected serially, wherein $n$ may be varied parametrically. For the NFE model: (1) the element cross-section is discretized into fibers; the web is discretized into fibers of $12.5 \mathrm{~mm} \mathrm{x}$ $12.5 \mathrm{~mm}$, whereas each flange is a single fiber, (2) strains at any point in the cross-section may be determined from curvatures based on the Plane-Sections-Remain-Plane (PSRP) assumption, (3) stress-resultants at the cross-section (i.e., axial forces and moments) are determined by integrating stresses in individual fibers, and (4) element end forces are determined through the principle of virtual displacements by integrating cross-sectional forces determined at 5 Gauss points along the length. The model has the ability to assign any constitutive model to any of the fibers. However, in a departure from conventional fiber models, the NFE allow computation of nonlocal strain at any Gauss point within any fiber by operating on strains from neighboring Gauss points, and even neighboring elements. The NFE models constructed as discussed above, provide the numerical infrastructure for implementing the nonlocal formulation. This comprises the following steps, executed sequentially :

1. Recovery of information from the CFE simulations, that may be used to inform the NFEmodels; this includes buckled shape profiles, localization length and its cross-sectional variation, stress-strain response over these localized regions, and corresponding load deformation response. Since these simulations have been validated by test data to represent physical phenomena associated with local buckling, information obtained from them may based on the benchmark response obtained from the CFE simulations (from Step 1 above), and the prior formulation for single-fiber element buckling (Kolwankar et al., 2017). 
This peer-reviewed published paper appears as: Kolwankar, S., Kanvinde, A., Kenawy, M., Lignos, D.G., Kunnath, S. (2018). "Simulating Local Buckling-Induced Softening in Steel Members Using an Equivalent Nonlocal Material Model in Displacement-Based Fiber Elements, ASCE

Journal of Structural Engineering, Vol. 144(10): 04018192-1, doi: 10.1061/(ASCE)ST.1943-541X.0002189

3. Implementation of this formulation within the NFE model in OpenSees, in a manner that allows for user-friendly simulation of frame structures with local buckling induced softening and localization.

4. Assessment of the implemented formulation against experimental data, as well as CFE benchmark response, and development of guidelines for the calibration and use of this implemented formulation.

\section{Continuum Finite Element (CFE) Models of Beam Columns}

The CFE simulations provide benchmark data for local buckling response of beam-columns under bending and axial load. To this end, the CFE models reproduce aspects of physical response that control local buckling, namely large deformations and nonlinear elastoplastic response. Figure 3a illustrates a deformed mesh (showing contours of plastic strain) of a CFE simulation for Test Problem \#42 (W16x89, $P / P_{y}=0.3, M / V=1875 \mathrm{~mm}$ - see Table 1). To construct these models, protocols developed by Elkady and Lignos (2015) were used. These models utilized shell elements (4 node reduced integration; S4R in ABAQUS). Each model was meshed using element size on the order of $25 \mathrm{~mm} \times 25 \mathrm{~mm}$. Mesh convergence studies by Elkady and Lignos (2015) indicate that this level of mesh refinement is able to appropriately represent stress gradients due to local buckling. Initial imperfections were introduced into the model as perturbations to initiate local buckling. The size and shape of these imperfections was based on procedures developed by Elkady and Lignos (2015). The constitutive response of the material was represented through a von Mises yield surface, supplemented by combined isotropic-kinematic hardening as per the ArmstrongFrederick (1966) model. The parameters of the model were calibrated to represent low-carbon Grade 50 steel (A992) commonly used in United States construction (see Elkady and Lignos, 2015 for values). It is relevant to note here that this constitutive model is monotonically hardening, implying that softening-induced mesh convergence is not encountered. Fixed boundary conditions 
This peer-reviewed published paper appears as: Kolwankar, S., Kanvinde, A., Kenawy, M., Lignos, D.G., Kunnath, S. (2018). "Simulating Local Buckling-Induced Softening in Steel Members Using an Equivalent Nonlocal Material Model in Displacement-Based Fiber Elements, ASCE Journal of Structural Engineering, Vol. 144(10): 04018192-1, doi: 10.1061/(ASCE)ST.1943-541X.0002189

were applied at one end of the column whereas axial forces and lateral displacements were applied at the other. Depending on the test problem (see Table 1), axial force was applied either simultaneously (i.e., proportionally) with the lateral displacement, or in advance and then held constant during application of lateral displacement. In each case, the axial force was a "follower" force, meaning that it did not induce additional P-delta moments about the fixed end. Elkady and Lignos (2015) extensively validated models constructed with this protocol and determined that they reproduced not only the load-deformation response, but also local response (including buckled shapes and strain distributions) with high accuracy. Residual stresses were not considered either in the CFE simulations or the fiber formulations discussed later; this follows observations by Newell and Uang (2006) and Elkady and Lignos (2012) who determined that residual stresses do not significantly affect response of compact wide-flanged sections, which undergo yielding prior to local buckling.

As a representative example, Figure 3a shows a photograph of a specimen identical to Test Problem \#42 (simulated by the FE model in Figure 3b) at the same deformation level as the FE model; the agreement in the deformed shape, as well a similar correspondence between the load deformation plots in Figure 3c indicates fidelity of the simulation. Validated in this manner, results from the FE models may be considered proxies for "true" response for the purposes of developing and evaluating the line-element based model. The following subsections summarize specific information (in addition to the load-deformation curves) that was recovered from the FE models, and its implications for the nonlocal formulation.

\section{Localization length (Characteristic length for nonlocal formulation)}

Physical length scales, associated with localization phenomena (local buckling in this case) are critical from the standpoint of mitigating mesh dependence through the NFE model. In a generic 
This peer-reviewed published paper appears as: Kolwankar, S., Kanvinde, A., Kenawy, M., Lignos, D.G., Kunnath, S. (2018). "Simulating Local Buckling-Induced Softening in Steel Members Using an Equivalent Nonlocal Material Model in Displacement-Based Fiber Elements, ASCE Journal of Structural Engineering, Vol. 144(10): 04018192-1, doi: 10.1061/(ASCE)ST.1943-541X.0002189

sense, the localization length denotes the distance over which strains increase accompanied by softening, while the adjacent (non-localized regions) unload elastically (i.e., strains decrease) to maintain equilibrium with the softening localized zone. In the context of buckling, the softening does not occur at the continuum scale, because the material at any continuum location hardens monotonically with respect to the continuum strain. Rather, the rotation of the buckling elements (e.g., flange segments) manifests itself as an effective longitudinal strain. Figure 4a (which shows representative simulation results) illustrates the genesis of this strain as it pertains to the projection of the flange rotations on the member axis. When the "effective" stress-strain response is considered at this scale (i.e., in a uniaxial sense over the length of the buckle), the aforementioned softening behavior is observed along with the attendant localization length, within which the projected strains increase while the stresses (also projected along the member axis) decrease. This occurs because flange rotation within this zone diminishes the longitudinal component of flange stress, even as the continuum stress itself increases due to material hardening. With this background, the localization length is determined at each loading step of each simulation to determine an instantaneous value of the localization length. Furthermore, this instantaneous value of localization length is determined at multiple locations through the width of the flange (i.e., in the z- direction, in Figure 4b). The process for determination of localization length is as follows: 1. At each $(x, z)$ location in the flange (see Figure $4 \mathrm{~b}$ for reference coordinate system) the instantaneous effective strain is determined as per the following formula:

$$
\varepsilon_{\text {effective }}(x, z)=\frac{\left|\overrightarrow{\Delta L^{\text {flange }}(x, z)}\right|-\left|\overrightarrow{\Delta L^{\text {flange }}(x, z)} \cdot \overrightarrow{\Delta L^{\text {web-centerline }}(x)}\right|}{\left|\overrightarrow{\Delta L_{0}^{\text {web-centerline }}(x)}\right|}
$$

In the above formula, $\overrightarrow{\Delta L^{\text {flange }}(x, z)}$ (defined at any location on the flange) is a sufficiently small vector representing the local orientation and length of a line segment on the flange 
This peer-reviewed published paper appears as: Kolwankar, S., Kanvinde, A., Kenawy, M., Lignos, D.G., Kunnath, S. (2018). "Simulating Local Buckling-Induced Softening in Steel Members Using an Equivalent Nonlocal Material Model in Displacement-Based Fiber Elements, ASCE

Journal of Structural Engineering, Vol. 144(10): 04018192-1, doi: 10.1061/(ASCE)ST.1943-541X.0002189

253 located at $(x, z)$ which represents the initial (undeformed) coordinates. The vector $\widehat{\Delta L^{\text {web-centerline }}(x)}$ is a similar vector at the centerline of the web located at the same longitudinal coordinate $x$ (for the web, $z=0$ ). As such, the numerator on the right-hand side of Equation 1 represents the effective reduction in length due to rotation of the flange in the local buckle. The location, based on the displacements recovered from the CFE simulations. Projection on the deformed web centerline $\overrightarrow{\Delta L^{\text {web-centerline }}(x)}$, rather than the undeformed longitudinal axis denominator $\left|\overrightarrow{\Delta L_{0}^{\text {web-centerline }}(x)}\right|$ represents the magnitude of a corresponding line segment at the web centerline in the undeformed state. These terms are determined numerically at each

2. Once the projected strains $\varepsilon_{\text {effective }}(x, z)$ are determined in this manner, strain rates (with respect to analysis-time) at each location $\dot{\varepsilon}_{\text {effective }}(x, z)$ may be determined through numerical differentiation over loading increments.

3. At any instant before the initiation of local buckling, all fibers in the compression flange undergo compression, i.e., the strain rate is negative (compressive) throughout the length of the flange. After local buckling, the localized strains result in a contiguous zone within which the projected strain $\dot{\varepsilon}_{\text {effective }}(x, z)$ rate is negative (i.e., the buckling zone), whereas the strain rate outside it is positive (i.e., the unloading zone). Figure $4 \mathrm{~b}$ illustrates the spatial extent of this localized zone for the simulation shown in Figure 4a. Observations are qualitatively similar for all other simulations. Referring to this figure, the length of this zone (denoted $l_{l o c}$ at any location along the flange) is the greatest along the flange tip (this value is denoted $l_{l o c}^{\max }$ ) and 
This peer-reviewed published paper appears as: Kolwankar, S., Kanvinde, A., Kenawy, M., Lignos, D.G., Kunnath, S. (2018). "Simulating Local Buckling-Induced Softening in Steel Members Using an Equivalent Nonlocal Material Model in Displacement-Based Fiber Elements, ASCE

Journal of Structural Engineering, Vol. 144(10): 04018192-1, doi: 10.1061/(ASCE)ST.1943-541X.0002189

274 decreases towards the web. Figure 4c shows the temporal evolution of $l_{l o c}^{\max }$. Referring to this

275 figure, the term $l_{l o c}^{\max }$ is a constant before localization, indicating that the effective strain

$276 \dot{\varepsilon}_{\text {effective }}(x, z)$ decreases along the entire compression flange - due to non-localized cantilever

277 bending. Figure $4 \mathrm{c}$ shows the evolution of the localized length $l_{\text {loc }}^{\max }$ (versus applied deformation expressed as percent drift) for the representative simulation. However, the length of this zone drops suddenly at the onset of localization (on average at a column drift angle $\Delta / L$ between $4-6 \%$ ), and remains unchanged thereafter. In the post-localization phase, the remainder of the compression flange undergoes a net increase in $\dot{\varepsilon}_{\text {effective }}(x, z)$, as it elastically unloads. The value $l_{l o c}^{\max }$ is appropriate from the standpoint of incorporation into the NFE model, since it subsumes the entire localized zone. It is observed for all the test problems that $l_{\text {loc }}^{\max }$ is directly proportional to the flange width and relatively insensitive to other model parameters, including moment gradient (which may otherwise be expected to nominally affect the plastic hinge length, and consequently the characteristic length) or axial load, such that the relationship $l_{\text {loc }}^{\max }=1.5 \times b_{f}$ (where $b_{f}$ is the flange width) is an excellent predictor of the localized length. Figure $4 \mathrm{c}$ shows this for one of the test problems. While it is noted that that the constant 1.5 is specific to this study, it is consistent with the results of Lay (1965) who determined the length of a local buckle in a wide-flanged section in flexure to be approximately the buckling flange. However, localization is not noted in the web (along with the central portion of the flange - refer Figure $4 b$ ) such that all fibers in this region continue to show monotonic 
This peer-reviewed published paper appears as: Kolwankar, S., Kanvinde, A., Kenawy, M., Lignos, D.G., Kunnath, S. (2018). "Simulating Local Buckling-Induced Softening in Steel Members Using an Equivalent Nonlocal Material Model in Displacement-Based Fiber Elements, ASCE

Journal of Structural Engineering, Vol. 144(10): 04018192-1, doi: 10.1061/(ASCE)ST.1943-541X.0002189

296 increase in effective stress-strain response, until the flange shows localization at which point

297 elastic unloading occurs. Following this, as discussed in the next section, only the flange is

298 simulated as a softening material in the NFE model; the web is simulated as a monotonically

299 hardening local material.

300

301

302

303

304

305

306

307

308

309

310

311

312

313

314

315

316

317

318

\section{Fiber stress-strain response}

To inform the NFE formulation, stress-strain response for the localized region of the flange was recovered from the CFE models. Figure 4d shows such response. Referring to Figure 4d (and Figure 4a introduced previously), the projected strain is determined by integrating $\varepsilon_{\text {effective }}(x, z)$ over the entire length of the localized zone, whereas the longitudinal stress $\sigma$ is recovered from the finite elements adjacent to the localized zone. Note that the stress-strain response shown in Figure $4 \mathrm{~d}$ is calculated for the entire width of the flange, rather than for individual fibers (or $z-$ locations). The stress values in the figure represent an average stress through the width. Similarly, the strain is determined by computing the average longitudinal strain over the flange width. Consequently, the curves represent the aggregated response of the entire buckling flange. Characterizing the constitutive response in this manner (rather than for individual fibers through the flange width) is expedient within the scope of the 2-d line-element formulation for uniaxial bending, which cannot accommodate variation in stresses or strains in the out-of-plane direction. As expected, the resulting curve shows an initial elastic region followed by a well-defined peak and a negative slope. At increasing deformations, the steepness of the descending branch decreases (i.e., it flattens out). This type of postbuckling response is well-documented across various components (Krawinkler et al., 1983, Lee and Stojadinovic, 1996; Ikeda and Mahin, 1986), and occurs when the destabilizing $P-\delta$ effects within the flange saturate as the buckle amplitude approaches a maximum value. It is relevant to note here that the post-peak response of the fiber as 
This peer-reviewed published paper appears as: Kolwankar, S., Kanvinde, A., Kenawy, M., Lignos, D.G., Kunnath, S. (2018). "Simulating Local Buckling-Induced Softening in Steel Members Using an Equivalent Nonlocal Material Model in Displacement-Based Fiber Elements, ASCE Journal of Structural Engineering, Vol. 144(10): 04018192-1, doi: 10.1061/(ASCE)ST.1943-541X.0002189

319 shown in Figure 4d is dependent on the gage length (i.e., the localized length) over which strains are measured. As such, the post-peak response is meaningless without this accompanying lengthscale. This underscores the importance of retaining this value and incorporating it as the characteristic length in the nonlocal model. Approximating the curvilinear response of the CFE models with this trilinear backbone is judicious for the following reasons: (1) it functionally represents the CFE response with reasonable accuracy, notwithstanding some deviation from it at large post-buckling deformations, (2) it enables the convenient parametrization of key response quantities, e.g., the peak strain and other quantities indicated in Figure 4d, which may be generalized across various configurations/crosssections as discussed later, and (3) multilinear stress-strain or load-deformation relationships are commonly used for component simulation (e.g., see ASCE 41-13), such that existing implementations of trilinear models may be used, without the need for developing a new constitutive model. As an example, the Modified-Ibarra-Medina-Krawinkler constitutive model (Ibarra et al., 2005), which is currently implemented in OpenSees (2012) includes a trilinear backbone similar to the one shown in Figure 4d. Referring to Figure 4d, the trilinear response is defined by 6 parameters: (1) the elastic modulus $E,(2)$ the yield stress $\sigma_{y},(3)$ the hardening ratio $h$ such that the hardening modulus is $h \times E$, (4) the critical stress corresponding to localization $\sigma_{c r},(5)$ the stress $\sigma_{\text {res }}$ and (6) the strain $\varepsilon_{\text {res }}$ that define the onset and height of the residual stress plateau. These are discussed in greater detail in the section describing their calibration and generalization. Based on these parameters, the stress-strain response may be expressed as follows:

$$
\sigma=E \cdot \varepsilon \text { for } \varepsilon \leq \sigma_{y} / E
$$


This peer-reviewed published paper appears as: Kolwankar, S., Kanvinde, A., Kenawy, M., Lignos, D.G., Kunnath, S. (2018). "Simulating Local Buckling-Induced Softening in Steel Members Using an Equivalent Nonlocal Material Model in Displacement-Based Fiber Elements, ASCE Journal of Structural Engineering, Vol. 144(10): 04018192-1, doi: 10.1061/(ASCE)ST.1943-541X.0002189

$$
\sigma=\sigma_{y}+h \cdot E \cdot\left(\varepsilon-\varepsilon_{y}\right) \text { for } \varepsilon_{y}<\varepsilon \leq \varepsilon_{c r}=\varepsilon_{y}+\left(\sigma_{c r}-\sigma_{y}\right) /(h \times E)
$$

$$
\sigma=\sigma_{c r}-\left(\varepsilon-\varepsilon_{c r}\right) \cdot\left(\sigma_{c r}-\sigma_{r e s}\right) /\left(\varepsilon_{r e s}-\varepsilon_{c r}\right) \text { for } \varepsilon_{c r}<\varepsilon \leq \varepsilon_{r e s}
$$

$$
\sigma=\sigma_{\text {res }} \text { for } \varepsilon>\varepsilon_{\text {res }}
$$

344

345

346

347

348

The above equations represent a functional form which requires additional adaptation for the nonlocal formulation (discussed in the next section). Specifically, the nonlocal strain quantity $\varepsilon^{*}$

is derived from the above functional form, such that $\varepsilon^{*}$ is a spatially averaged total strain (as referenced above), except that it is invoked only after the attainment of peak stress $\sigma_{c r}$. The next section discusses the development of the nonlocal formulation based on these qualitative and quantitative insights. Tensile response of the material (not shown in Figure 4d) is represented as bilinear hardening (as defined by the parameters $E, \sigma_{y}$, and $h$ ) without the softening branches.

\section{IMPLEMENTATION OF NONLOCAL FORMULATION FOR FIBER-BASED LINE ELEMENT}

The nonlocal formulation is implemented within the NFE model discussed previously (Fig. 2). To provide context for the mathematical form of the formulation, it is useful to first establish the computational framework within which it is realized. A brief overview follows:

1. Applied incremental loads or displacements or forces (e.g., at the tip of the cantilever in Figure 2) along with a tangent stiffness matrix are used to calculate a trial incremental nodal displacement vector. This tangent stiffness matrix is computed from local strains from the previously converged step. Although a consistent tangent matrix based on the nonlocal strains (e.g., Jirasek and Patzak, 2002) would accelerate convergence, the derivation of such a tangent matrix is outside the scope of this work. 
This peer-reviewed published paper appears as: Kolwankar, S., Kanvinde, A., Kenawy, M., Lignos, D.G., Kunnath, S. (2018). "Simulating Local Buckling-Induced Softening in Steel Members Using an Equivalent Nonlocal Material Model in Displacement-Based Fiber Elements, ASCE

Journal of Structural Engineering, Vol. 144(10): 04018192-1, doi: 10.1061/(ASCE)ST.1943-541X.0002189

3612 2. The incremental displacement vector (along with displacements from the previously converged load step) is used to determine curvatures and axial strains along the length of each element (i.e., at each Gauss integration point), using shape functions. These are subsequently converted to local fiber strains based on the PSRP assumption.

3. Nonlocal strains are computed at each Gauss point by applying the formulation (discussed subsequently in this section) to local strains (as determined in Step 2 above) in the

4. The softening constitutive relationship (represented by the trilinear backbone, as shown in Figure 4d) is used to determine stresses in each fiber at each Gauss point; these stresses are integrated to conduct force-recovery, i.e., to determine cross-sectional and finally nodal forces nonlocal averaging operation, (2) the constitutive relationship, and (3) operational details. 
This peer-reviewed published paper appears as: Kolwankar, S., Kanvinde, A., Kenawy, M., Lignos, D.G., Kunnath, S. (2018). "Simulating Local Buckling-Induced Softening in Steel Members Using an Equivalent Nonlocal Material Model in Displacement-Based Fiber Elements, ASCE Journal of Structural Engineering, Vol. 144(10): 04018192-1, doi: 10.1061/(ASCE)ST.1943-541X.0002189

Nonlocal strain definition

The primary objective of the nonlocal strain measure is to facilitate the introduction of a physical

length scale into the constitutive response, to mitigate mesh dependence. A previously developed

formulation (Kolwankar et al., 2017) for single-fiber response is adapted to the fiber formulation, strains inside the localized zone. Equations 6-9 below show the expressions for calculating the nonlocal strain $\varepsilon^{*}$.

$$
\varepsilon^{*}=m \cdot \varepsilon^{w}+(1-m) \cdot \varepsilon
$$

392

394 395 396 The term $\varepsilon^{w}$ is a weighted average of strain in the neighborhood of any point:

$$
\varepsilon^{w}(x)=\int_{L_{c}} \alpha(x, \xi) \cdot \varepsilon(x, \xi) \cdot d \xi
$$

The term $\alpha(x, \xi)$ represents a weighting function defined over the length $L_{c}$, and $\xi$ is a local variable, such that a bell-shaped weighting function may be generated as:

$$
\alpha(x, \xi)=\frac{\alpha^{\prime}(x, \xi)}{\int_{L_{c}} \alpha^{\prime}(x, \xi) \cdot d \xi}
$$

397 In which,

$$
\alpha^{\prime}(x, \xi)=\frac{15}{8 \cdot L_{c}}\left(1-\frac{4 \cdot(x-\xi)^{2}}{L_{c}^{2}}\right) \text { for }|x-\xi| \leq L_{c} / 2 ; \alpha^{\prime}(x, \xi)=0 \text { for }|x-\xi|>L_{c} / 2
$$
termed an "over-nonlocal" formulation (Vermeer and Brinkgreve, 1994), combining the commonly used form of nonlocal strain (usually determined as $\varepsilon_{p}^{w}$ ), and the local strain $\varepsilon$. The 
This peer-reviewed published paper appears as: Kolwankar, S., Kanvinde, A., Kenawy, M., Lignos, D.G., Kunnath, S. (2018). "Simulating Local Buckling-Induced Softening in Steel Members Using an Equivalent Nonlocal Material Model in Displacement-Based Fiber Elements, ASCE

Journal of Structural Engineering, Vol. 144(10): 04018192-1, doi: 10.1061/(ASCE)ST.1943-541X.0002189

402 parameter $m$ determines the relative contribution of these two components while providing an 403 additional degree of freedom (or parameter) in the model for more accurate simulation of the load-

404 displacement response as well as strain distributions. For this study, $m$ is selected as 1.5 following

405 the work of Kolwankar et al. (2017), whereas $L_{c}$ is selected as $1.5 \times b_{f}$, since it is the best estimate

406 of physical length scale $l_{l o c}^{\max }$ associated with local buckling as discussed earlier.

\section{Softening Constitutive Relationship}

408 Referring to Figure 4d and associated discussion, a trilinear curve is used to represent buckling409 induced softening response in compression, whereas a bilinear curve is used to represent tensile 410 yielding response. This results in 6 parameters, which may be calibrated to provide the best fit 411 with the curve obtained for a particular geometric/loading configuration, i.e., for each of the test

412 problems listed in Table 1. While this type of case-by-case calibration may potentially result in the 413 best possible fit with test data, it cannot be generalized to different members or configurations. 414 Consequently, for all 6 parameters in the constitutive model, best practices were developed to 415 facilitate general calibration:

416 1. The parameters $E, \sigma_{y}$, and $h$ may be used directly from uniaxial material tensile coupon (or

417 specified) data since they do not pertain to localization. In case $h$ cannot be conveniently 418 determined from coupon tests, a value of 0.05 is recommended, following the work of Elkady $419 \quad$ and Lignos (2015).

2. The critical stress $\sigma_{c r}$ at which local buckling initiates is approximated by the following equation:

$$
\sigma_{c r}=1.1 \times \sigma_{u}-2.17 \frac{b_{f}}{2 t_{f}}
$$


This peer-reviewed published paper appears as: Kolwankar, S., Kanvinde, A., Kenawy, M., Lignos, D.G., Kunnath, S. (2018). "Simulating Local Buckling-Induced Softening in Steel Members Using an Equivalent Nonlocal Material Model in Displacement-Based Fiber Elements, ASCE Journal of Structural Engineering, Vol. 144(10): 04018192-1, doi: 10.1061/(ASCE)ST.1943-541X.0002189

423

424

425

426

427

428

429

430

431

432

433

434

435

436

437

438

In the above equation, $\sigma_{u}$ is the ultimate strength of the material, whereas $b_{f} / 2 t_{f}$ is the flange

width-thickness ratio. The expression above is a regressed relationship (against data from all the CFE simulations, with $R^{2}=0.95$ ), which reflects the dependence of the flange local buckling strength on the width-thickness ratio. Various similar relationships were trialed (and researched in literature), and the influence of other parameters, including web slenderness and material hardening, was examined. In conclusion it was determined that the flange widththickness is the dominant parameter controlling local buckling. The dominance of $b_{f} / 2 t_{f}$ in controlling local buckling is well-documented, such that it is routinely used as a basis for member selection and design (AISC, 2016). Furthermore, the use of $b_{f} / 2 t_{f}$ as the sole parameter is supported by the work of Hartloper and Lignos (2017), because for hot-rolled cross-sections, $b_{f} / 2 t_{f}$ and the web slenderness ratio $h / t_{w}$ are well-correlated.

3. Expressions for the parameters $\sigma_{r e s}$ and $\varepsilon_{\text {res }}$ defining the descending branches of the softening relationship are regressed as functions of $b_{f} / 2 t_{f}$ (in a manner similar to that outlined above for $\sigma_{c r}, R^{2}=0.56$ and 0.98 for equations 11 and 12 , respectively):

$$
\begin{array}{r}
\varepsilon_{r e s}=0.15-0.014 \frac{b_{f}}{2 t_{f}} \geq \frac{\sigma_{y}}{E}+\frac{\sigma_{c r}-\sigma_{y}}{h \times E} \\
\sigma_{r e s}=\sigma_{y}-1.44 \frac{b_{f}}{2 t_{f}} \geq 0
\end{array}
$$

439 Similar to $\sigma_{c r}$, the flange width-thickness ratio is the dominant quantity controlling these parameters as well. It is noted here that the above approaches for estimating these parameters are provided mainly for convenience, and do not materially impact the nonlocal formulation itself. 
This peer-reviewed published paper appears as: Kolwankar, S., Kanvinde, A., Kenawy, M., Lignos, D.G., Kunnath, S. (2018). "Simulating Local Buckling-Induced Softening in Steel Members Using an Equivalent Nonlocal Material Model in Displacement-Based Fiber Elements, ASCE

Journal of Structural Engineering, Vol. 144(10): 04018192-1, doi: 10.1061/(ASCE)ST.1943-541X.0002189

442 More refined estimates or approaches may be used if additional data is available for specific

443 materials or configurations (e.g., Torabian and Schafer, 2014).

\section{Operational Details}

445 In addition to the two main components of the formulation described above, some other details are important from an operational standpoint. These include:

447

448
- Providing sufficient mesh density over the localized zone, to prevent localization within one element. This is discussed in greater detail in a subsequent section.

- Introduction of perturbations (in the form of slightly reduced area (2\% less than the nominal flange area) at fixed intervals along its length. The interval is selected to be on the order of $b_{f}$ to reflect imperfection patterns measured by Elkady and Lignos (2015) and also used in the CFE simulations. These are usually not activated in simulations with moment gradients, but are introduced to trigger localization in simulations with constant moment.

- In addition to the above points, some other operational processes (that do not influence the final solutions) are adopted to aid convergence. These include: (1) nonlocal strain averaging is invoked only after the peak stress $\sigma_{c r}$ is attained, (2) the nonlocal averaging is conducted for the total, rather than the plastic strain, and (3) the unloading slope (which is activated in the regions-outside the localized zone) is assumed equal to the elastic modulus $E$.

The line-element formulation as described in this section is used to simulate all the test problems shown earlier in Tables 1, and 2 experiments conducted previously by Lignos et al., (2016). Results of these simulations, when compared to corresponding CFE or experimental results may be used to examine efficacy of the proposed approach - especially as it pertains to mesh sensitivity of the load-deformation response and deformation distribution. This is discussed in the next section. 
This peer-reviewed published paper appears as: Kolwankar, S., Kanvinde, A., Kenawy, M., Lignos, D.G., Kunnath, S. (2018). "Simulating Local Buckling-Induced Softening in Steel Members Using an Equivalent Nonlocal Material Model in Displacement-Based Fiber Elements, ASCE

Journal of Structural Engineering, Vol. 144(10): 04018192-1, doi: 10.1061/(ASCE)ST.1943-541X.0002189

RESULTS AND DISCUSSION

465 Each of the test-problems summarized in Table 1 was simulated through the line-element based model and the nonlocal formulation, implemented as outlined in the preceding section. Selected results from these simulations are illustrated in Figures 5-7. Figures 5a-i compare the efficacy of conventional fiber based elements and the NFE approach to simulate the load-deformation response (as determined from the CFE). Of these, Figures 5a-c show load-deformation curves determined from the conventional fiber-based line element models for three loading cases (with $P / P_{y}=0,0.2$, and 0.5 , and $M / V=4500 \mathrm{~mm}$, all for W24X146, i.e., Test Problems \#17-19). The conventional fiber-models utilize the trilinear backbone model and its attendant calibration (as outlined in the preceding section and Equations 10-12). However, they do not include the nonlocal

474 formulation and the associated length scale. The load-deformation curves from these models are 475 overlaid on their counterparts from the CFE simulations, which may be considered objective 476 benchmark responses. The line-element based models include 25,45 , and 85 elements to examine 477 the influence of mesh-density on the load deformation curve. Referring to Figures 5a-c, the 478 following observations may be made:

- As expected, an increase in axial load ratio results in a decrease in peak strength and steeper

480 (i.e., more rapidly decreasing) post-peak response.

- The conventional fiber models reproduce peak strength accurately, since they are able to capture $P-M$ interactions and utilize estimates of $\sigma_{c r}$ (Equation 10) that reflect true response with good accuracy. However, the limitations of the conventional approach become apparent during the post peak response, in which significant mesh-sensitivity is observed along with deviation from the CFE response. 
This peer-reviewed published paper appears as: Kolwankar, S., Kanvinde, A., Kenawy, M., Lignos, D.G., Kunnath, S. (2018). "Simulating Local Buckling-Induced Softening in Steel Members Using an Equivalent Nonlocal Material Model in Displacement-Based Fiber Elements, ASCE Journal of Structural Engineering, Vol. 144(10): 04018192-1, doi: 10.1061/(ASCE)ST.1943-541X.0002189

486 Figures 5d-i are similar to Figures 5a-c, except that they show results from the NFE models with 487 the nonlocal formulation developed in this study. These figures also show results for three 488 additional load cases, corresponding to $M / V=2250 \mathrm{~mm}$ (Test Problems \#20-22). An examination of the figures reveals the following:

490

491

492

493

494

495

496

497

498

499

500

501

502

503

504

505

506

507

508

- Similar to the conventional fiber models, the NFE models replicate pre-peak load-deformation response (of the CFE models) with reasonable accuracy. Additionally, the NFE models are able to track post-peak response for all the loading cases with good accuracy even to large drifts $(\sim 10 \%)$, indicating that the approach effectively simulates $P-M$ interaction as well as moment gradient effects. A similar agreement is observed for proportionally loaded specimens (albeit not shown in Figure 5). Importantly, this response is mesh-independent, such that the load deformation curves corresponding to the different element sizes are virtually coincident.

- In the latter stages of response, the load from the CFE simulations drops somewhat uniformly, whereas that from the NFE stabilizes slightly - this is particularly notable for Figures $5 \mathrm{~h}$ and i. For Figure 5h, this appears to be an artifact of the Ibarra et al., (2005) implementation of the trilinear backbone which has an ideally flat residual stress-capacity, and may be suitably overcome by prescribing a constitutive relationship that more closely follows the measured response. For Figure 5i, the peak load itself is mischaracterized by both the nonlocal approach. This configuration has a high axial load $P / P_{y}=0.5$, suggesting that the calibrated parameters of the trilinear backbone (specifically $\sigma_{c r}$ ) do not reflect the peak stress associated with flange local buckling under a combination of high axial and flexural loads.

- The agreement in Figures 5d-i is notable, given that neither the nonlocal formulation, nor the constitutive parameters were back calibrated (or refined) based on the global load-deformation curve. In fact, the constitutive parameters (which are defined for local flange stress-strain 
This peer-reviewed published paper appears as: Kolwankar, S., Kanvinde, A., Kenawy, M., Lignos, D.G., Kunnath, S. (2018). "Simulating Local Buckling-Induced Softening in Steel Members Using an Equivalent Nonlocal Material Model in Displacement-Based Fiber Elements, ASCE Journal of Structural Engineering, Vol. 144(10): 04018192-1, doi: 10.1061/(ASCE)ST.1943-541X.0002189 response) were determined from Equations 10-12. This indicates that the approach up-scales fiber-level post-peak softening response to obtain global response in a reasonable manner. However, some discrepancies are noted as well, especially in latter stages of deformation.

A similar analysis of the deformation patterns simulated by the line-based nonlocal model (relative to the CFE model) requires some discussion to contextualize the results. Figure 6 shows a representative plot of a post-localization curvature profile (for Test Problem \#20 at $8 \%$ drift) as determined from the CFE simulation. The curvatures are back-calculated by dividing the projected strains at the extreme fibers (as determined from Equation 1) by the section depth. Overlaid on this plot is the curvature profile (for the same test-problem and loading step) as recovered directly from the NFE model (with 45 elements). Referring to the two curves, it is noted that the curvature profile from CFE model resembles a double-plateau shape, which arises from the double-plateau shape of the projected flange strain profile discussed earlier, in addition to the slight stagger between the flange buckle on either side of the web (Figure $4 b$ ). In its current form, the NFE model is unable to capture this response, which is the result of the complex buckling mode. As a result, the curvature localizes (as one peak) in the region closest to the support, where the moment is highest. With this context, the efficacy of the line-element based model to simulate deformation/strain distribution is assessed in the context of its ability to characterize the length of the localized zone and the peak curvature in a mesh-independent manner. More specifically, although the curvature values as determined the NFE simulations are not meaningful in an absolute sense, they may be integrated over the localized zone to provide a sense of the overall deformation in the localized zone. Perhaps more importantly, the NFE-inferred curvature may be used to assess local damage in a relative sense across different beam-columns with local buckling. With this background, Figures 7a-i show snapshots of the longitudinal curvature profiles for the same test problems as 
This peer-reviewed published paper appears as: Kolwankar, S., Kanvinde, A., Kenawy, M., Lignos, D.G., Kunnath, S. (2018). "Simulating Local Buckling-Induced Softening in Steel Members Using an Equivalent Nonlocal Material Model in Displacement-Based Fiber Elements, ASCE Journal of Structural Engineering, Vol. 144(10): 04018192-1, doi: 10.1061/(ASCE)ST.1943-541X.0002189

532 shown in Figures 5a-i. To examine mesh-sensitivity in the line-element model, results are shown 533 from simulations with various element sizes. Figures 7a-c show results from a conventional fiber534 based line element, without the nonlocal formulation. In all cases, the main observations are essentially similar to that for the load deformation curve. Specifically, the conventional fiber model exhibits mesh-dependence such that the near the support, the curvature profile is controlled entirely by mesh density, with localization occurring in exactly one element. Figure 7a indicates this specifically, although a similar phenomenon is observed in Figures $7 \mathrm{~b}$ and $\mathrm{c}$ as well. This causes significant variation in the curvatures at any point within this zone. For purposes of illustration, this variation is indicated in Figure $7 \mathrm{a}$ for $\mathrm{x} / \mathrm{L}=0.05$. The implication is that these results cannot be interpreted meaningfully. On the other hand, the NFE-based model mitigates this mesh dependence, by smearing the localization length over several elements. As a result, the curvature profile (especially near the support) is controlled by the physical length scale rather than the mesh

544 size. Figure 8 provides further examination of the effect of mesh size, plotting the curvatures determined from NFE-based models at a distance $L_{c} / 2$ from the cantilever support, i.e., at the center of the localized zone, against $L_{c}$ / element size. These curvatures are recovered at

547 displacements well into the post-peak or localized regime for three test problems. Referring to the 548 figure, two observations may be made. First, as the mesh size is refined (i.e., $L_{c} /$ element size is increased), the curvatures converge - indicating that the non-objectivity is effectively mitigated.

550 Recall that for a conventional local formulation, the strains become unbounded as element size is 551 reduced. Second, for the test-problems shown (results for all other test problems are similar) this 552 convergence is observed at approximately $L_{c} /$ element size $=10$, suggesting an appropriate mesh 553 refinement for accurate simulation of post-peak response. As a point of reference, even with this 554 degree of refinement, the NFE cantilever model requires roughly $1 / 20^{\text {th }}$ to $1 / 50^{\text {th }}$ the time $(\sim 30$ 
This peer-reviewed published paper appears as: Kolwankar, S., Kanvinde, A., Kenawy, M., Lignos, D.G., Kunnath, S. (2018). "Simulating Local Buckling-Induced Softening in Steel Members Using an Equivalent Nonlocal Material Model in Displacement-Based Fiber Elements, ASCE Journal of Structural Engineering, Vol. 144(10): 04018192-1, doi: 10.1061/(ASCE)ST.1943-541X.0002189

555 seconds) to execute as compared to the counterpart CFE model ( 1200 seconds). Note that this estimate may vary significantly depending upon the hardware, other features of the software implementation (e.g., parallelization) as well as the complexity of the structure being analyzed as a result, this estimate is provided only to indicate that the NFE model does provide a substantial decrease in computational time for a set of problems. Notwithstanding the limitations of the curvature measure as illustrated in Figure 6, the NFE-based estimates of curvature offer an improvement over the conventional fiber model due to their mesh-independence, implying that they may be interpreted more meaningfully to assess damage.

As an additional validation exercise, the NFE models are used to predict response of 2 experiments on beam-columns (W16X89 with $P / P_{y}=0.3$ and 0.5 ) conducted by Lignos et al., (2016). Figure 9a shows a photograph of one of these experiments being conducted, whereas Figures $9 \mathrm{~b}$ and c overlay load-deformation curves from these experiments on corresponding predictions from the

567 NFE models with three mesh densities. The predictions are conducted in a blind sense, meaning that only the configurational parameters of the test specimen and setup are used to inform the fiber-

569 based model. To recapitulate, the characteristic length $L_{c}$ is calculated as $1.5 \times b_{f}$, whereas

570 parameters of the softening constitutive model are calculated from Equations 10-12; again, noting

571 that these estimates are not influenced by the experimental data. The figures indicate that when

572 calibrated as per the guidelines provided, the NFE models reproduce the experimental curves 573 (including the post-peak response) with high accuracy. The results are encouraging for the

574 following reasons: (1) the NFE models are not compromised by the mesh density, thereby 575 overcoming the main limitation of the conventional fiber-based approach, and (2) they are able to 576 capture differences in post-peak response across the two experiments with different axial loads - 
This peer-reviewed published paper appears as: Kolwankar, S., Kanvinde, A., Kenawy, M., Lignos, D.G., Kunnath, S. (2018). "Simulating Local Buckling-Induced Softening in Steel Members Using an Equivalent Nonlocal Material Model in Displacement-Based Fiber Elements, ASCE

Journal of Structural Engineering, Vol. 144(10): 04018192-1, doi: 10.1061/(ASCE)ST.1943-541X.0002189

577 by integrating fiber-scale constitutive response rather than calibration to large scale tests, thereby

578 retaining the key strength of the fiber approach.

\section{Summary, ConcluSiOnS, AND Limitations}

580 This article presents a nonlocal fiber-element based framework for simulating 2-d beam-column

581 elements, focused on rolled steel sections susceptible to local buckling-induced softening. The

582 approach overcomes the problem of non-objectivity (i.e., mesh-dependence) which is usually a

583 limitation of fiber based models, while retaining attractive features of fiber models such as the

584 ability to capture $P-M$ interaction, the initiation of plasticity at arbitrary locations, and its spread.

585 The approach provides a computationally efficient alternative to continuum finite element

586

587

588

589

590

591

592

593

594

595

596

597

598 modeling, which is currently the only viable approach for simulating local buckling-induced softening in an objective manner. To achieve this, the proposed approach up-scales recent work that demonstrated the use of a nonlocal formulation to simulate geometric nonlinearity induced softening (i.e., postbuckling response) in a single fiber to a complete frame element. The implementation in the open source software OpenSees is discussed, and guidelines for calibration and execution of the framework are outlined. The approach is informed by a comprehensive set of Continuum Finite Element simulations that examine a range of parameters including cross-section shape, moment gradient, and axial load ratio.

The main elements of this approach include: (1) estimation of the physical length scale associated with local buckling; (2) estimation of the effective post-buckling constitutive response at the fiber level; (3) idealized representation of this response through a softening constitutive model, which utilizes a nonlocal strain formulation; (4) numerical implementation within OpenSees, such that the user may designate physical beams or columns as single members, with the following inputs: 
This peer-reviewed published paper appears as: Kolwankar, S., Kanvinde, A., Kenawy, M., Lignos, D.G., Kunnath, S. (2018). "Simulating Local Buckling-Induced Softening in Steel Members Using an Equivalent Nonlocal Material Model in Displacement-Based Fiber Elements, ASCE Journal of Structural Engineering, Vol. 144(10): 04018192-1, doi: 10.1061/(ASCE)ST.1943-541X.0002189

599 (a) length scale, (b) parameters for the softening constitutive relationship, and (c) desired mesh 600 density; and (5) guidelines for calibration/selection of these inputs.

601

602

603

604

605

606

607

608

609

610

611

612

613

614

615

616

617

618

The implemented approach is used for prediction of the CFE simulations (both load-deformation response, and curvature distribution) as well as experimental results. The results are encouraging, in that the approach successfully mitigates mesh-dependence across a range of configurational parameters. Additionally, it effectively simulates the effect of $P-M$ interactions and moment gradient on load-deformation as well as deformation amplification within the localized zone. The latter is particularly attractive in contrast to other approaches for mitigation of non-objectivity in frame-elements, in which the softening response is adjusted in concert with the mesh size. As a result, it may be used for assessment of downstream damage states, through the use of appropriate damage/fracture models (e.g., Smith et al., 2016). The use of nonlocal formulations to simulate buckling-induced (or more generally, geometric nonlinearity-induced) softening is nascent, and as such the overall framework is still under development. Consequently, the framework has several limitations which must be considered in its usage, as also for future development. From a physical standpoint, the framework only addresses one form of localization and softening, that due to local buckling. Other forms, such as lateral-torsional or distortional buckling (Yu and Schafer, 2006) are not currently within its scope. Similarly, three-dimensional response modes of biaxial bending or torsion are not considered. Cyclic loading is similarly not addressed; this is possibly the most important area of future work.

Some aspects of response (e.g., participation of the web in the local buckling mode) were disregarded in favor of simplicity. Similarly, the local curvatures obtained from the NFE approach may be interpreted only in a relative sense, given its inability to reproduce the double-plateau curvature profile corresponding to local buckling. Moreover, since the parameters for the 
This peer-reviewed published paper appears as: Kolwankar, S., Kanvinde, A., Kenawy, M., Lignos, D.G., Kunnath, S. (2018). "Simulating Local Buckling-Induced Softening in Steel Members Using an Equivalent Nonlocal Material Model in Displacement-Based Fiber Elements, ASCE

Journal of Structural Engineering, Vol. 144(10): 04018192-1, doi: 10.1061/(ASCE)ST.1943-541X.0002189

622 constitutive model are calibrated to provide best fit with the data, caution should be exercised in 623 generalizing these to different members or configurations. Finally, the approach inherits some

624 structural limitations of the fiber approach, such as the Plane-Sections-Remain-Plane assumption.

625 Notwithstanding this, the proposed approach establishes the viability of using nonlocal

626 formulations to simulate geometric nonlinearity induced softening and localization in an objective

627 manner. The observed accuracy of the approach (especially for the blind predictions of the

628 experiments) is encouraging in itself. Perhaps most importantly, the approach provides a generic

629 framework which may be extended to simulate other aspects of physical response, by overcoming 630 the limitations outlined above.

631

632

633

634

635

636

637

638

639

640

641

642

643

644

645

646

647

\section{ACKNOWLEDGMENTS}

The work was supported by the National Science Foundation (Grant \#CMMI 1434300), as well as graduate fellowships from the University of California at Davis. The findings and opinions presented in this paper are entirely those of the authors.

\section{REFERENCES}

AISC (2016). "Seismic Provisions for Structural Steel Buildings." AISC 341-16, American Institute of Steel Construction, Chicago, IL.

Armstrong, P. J., and Frederick, C. O. (1966). A Mathematical Represenation of the Multiaxial Bauschinger Effect. Berkeley, UK: Berkeley Nuclear Laboratories, Research \& Development Dept.

ASCE 41-13 (2014). "Seismic Evaluation and Retrofit of Existing Buildings," American Society of Civil Engineers, Reston, VA.

Bazant, Z.P., (1976). “Instability, Ductility, and Size Effect in Strain-Softening Concrete,” Journal of Engineering Mechanics, American Society of Civil Engineers, 102, 331-344.

Bazant Z.P., and Jirasek, M. (2002). "Nonlocal integral formulations of plasticity and damage: Survey of progress,” Journal of Engineering Mechanics, 128(11) 1119-1149. 
This peer-reviewed published paper appears as: Kolwankar, S., Kanvinde, A., Kenawy, M., Lignos, D.G., Kunnath, S. (2018). "Simulating Local Buckling-Induced Softening in Steel Members Using an Equivalent Nonlocal Material Model in Displacement-Based Fiber Elements, ASCE

Journal of Structural Engineering, Vol. 144(10): 04018192-1, doi: 10.1061/(ASCE)ST.1943-541X.0002189

Bazant, Z. P., and Oh, B. H. (1983). "Crack band theory for fracture of concrete." Mat. and Struct., 16, 155-177.

Bazant, Z. P., and Planas, J. (1998). Fracture and size effect in concrete and other quasibrittle materials. CRC Press, Boca Raton, Fla.

Coleman, J. and Spacone, E. (2001).’Localization issues in force based frame elements," Journal of Structural Engineering, ASCE, 127(11) 1257-1265.

Computers and Structures, Inc., (2016). "ETABS: Integrated Building Design Software, Users Guide," Computers and Structures, Berkeley, CA, 2016.

Dides, M.A., and de la Llera, J.C., (2005). “A comparative study of concentrated plasticity models in dynamic analysis of building structures," Earthquake Engineering and Structural Dynamics, 34, 1005-1026.

di Prisco, M., and Mazars, J., (1996). "Crush-crack: A nonlocal damage model for concrete," Mechanics of Cohesive Frictional Materials, Wiley, 1(4), 321-347.

Elkady, A., and Lignos D. G., (2012). "Dynamic stability of deep slender steel columns as part of special MRFs designed in seismic regions: finite element modeling," In: Proc. first international conference on performance-based and life-cycle structural engineering (PLSE), Hong Kong, December 5-7, 2012.

Elkady, A., Lignos, D.G. (2015). “Analytical Investigation of the Cyclic Behavior and Plastic Hinge Formation in Deep Wide-Flange Steel Beam-Columns", Bulletin of Earthquake Engineering, Vol. 13 (4), 1097-1118, doi:10.1007/s10518-014-9640-y.

Engelen, R.A.B., Geers, M.G.D., Baaijens, F.P.T., (2003). "Nonlocal implicit gradient enhanced elasto-plasticity for the modeling of softening behaviour," International Journal of Plasticity, 19(4), 403-433.

Fell, B.V., Kanvinde, A.M., and Deierlein, G.G., (2010). "Large-scale testing and simulation of earthquake induced ultra low cycle fatigue in bracing members subjected to cyclic inelastic buckling,” Technical Report 172, John A. Blume Earthquake Engineering Center, Stanford University, CA 94305.

Federal Emergency Management Agency - FEMA. (2012). "FEMA P-58: Seismic Performance Assessment of Buildings," Washington, DC, USA.

Fogarty, J., and El-Tawil, S., (2015). "Collapse resistance of steel columns under combined axial and lateral loading," Journal of Structural Engineering, American Society of Civil Engineers, 142(1), 10.1061/(ASCE)ST.1943-541X.0001350. 
This peer-reviewed published paper appears as: Kolwankar, S., Kanvinde, A., Kenawy, M., Lignos, D.G., Kunnath, S. (2018). "Simulating Local Buckling-Induced Softening in Steel Members Using an Equivalent Nonlocal Material Model in Displacement-Based Fiber Elements, ASCE

Journal of Structural Engineering, Vol. 144(10): 04018192-1, doi: 10.1061/(ASCE)ST.1943-541X.0002189

680

681

682

683

684

685

686

687

688

689

690

691

692

693

694

695

696

697

698

699

700

701

702

703

704

705

706

707

708

709

710

711

712

Hamburger, R.O., Krawinkler, H., Malley, J.O., and Adan, S.M., (2009). "Seismic design of steel special moment frames: a guide for practicing engineers," NEHRP Seismic Design Technical Brief No. 2, produced by the NEHRP Consultants Joint Venture, a partnership of the Applied Technology Council and the Consortium of Universities for Research in Earthquake Engineering, for the National Institute of Standards and Technology, Gaithersburg, MD., NIST GCR 09-917-3

Hartloper, A., and Lignos, D., (2017). "Updates to the ASCE-41-13 provisions for the nonlinear modeling of steel wide-flange columns for performance-based earthquake engineering,"

Hibbitt, D., Karlsson, B., Sorensen, P. (2013). Abaqus/CAE user's guide, ABAQUS 6.11, Dassault Systèmes Simulia Corp., Providence, RI.

Ibarra, L.F., and Krawinkler, H., (2005). "Global Collapse of Frame Structures under Seismic Excitations," Technical Report 152, John A Blume Earthquake Engineering Center, Stanford University, CA.

Ibarra, L.F., Medina, R.A., Krawinkler, H. (2005). "Hysteretic models that incorporate strength and stiffness deterioration," Earthquake Engineering and Structural Dynamics, Wiley, 34: 1489-1511.

Ikeda, K. and Mahin. S.A. (1986). "Cyclic Response of Steel Braces.” J. Struct. Eng., ASCE, 112 (2), 342-361.

Jirásek, M., and Rolshoven, S., (2003). "Comparison of integral-type nonlocal plasticity models for strain-softening materials," International Journal of Engineering Science, 41(13-14), 1553-1602.

Jirásek, M., and Patzak, B., (2002). "Consistent tangent stiffness for nonlocal damage models," Computers \& Structures, 80, 14-15, 1279-1293.

Kasai, K., Nam, T., and Maison, B., (2016). "Structural collapse correlative analysis using phenomenological fiber hinge elements to simulate two-directional column deteriorations," Earthquake Engineering and Structural Dynamics, 45(10), 1581-1601.

Khaloo, A.R., and Tariverdilo, S., (2002). "Localization analysis of Reinforced Concrete Members and Softening Behavior," Journal of Structural Engineering, American Society of Civil Engineers, 128(9), 1148-1157.

Khaloo, A.R., and Tariverdilo, S., (2003). "Localization analysis in softening RC frame structures," Earthquake Engineering and Structural Dynamics, 32 (2), 207-227.

Kolwankar, S.S., Kanvinde, A.M., Kenawy, M., and Kunnath, S., (2017). "A uniaxial nonlocal formulation for geometric nonlinearity induced necking and buckling localization in a steel 
This peer-reviewed published paper appears as: Kolwankar, S., Kanvinde, A., Kenawy, M., Lignos, D.G., Kunnath, S. (2018). "Simulating Local Buckling-Induced Softening in Steel Members Using an Equivalent Nonlocal Material Model in Displacement-Based Fiber Elements, ASCE

Journal of Structural Engineering, Vol. 144(10): 04018192-1, doi: 10.1061/(ASCE)ST.1943-541X.0002189 bar," Journal of Structural Engineering, American Society of Civil Engineers. 143(9): 04017091.

Krawinkler, H., Zohrei, M., Lashkari-Irvani, B., Cofie, N.G., Hadidi-Tamjed, H., (1983). "Recommendations for Experimental Studies on the Seismic Behavior of Steel Components and Materials," Technical Report 61, John A. Blume Earthquake Engineering Center, Stanford University, CA.

Lay, M.G., (1965). "Some studies of flange local buckling in wide flange shapes," Fritz Engineering Laboratory, Report 297.10, 1965, Lehigh University, Bethlehem, PA.

Lee, K., and Stojadinovic, B., (1996). "A plastic collapse method for evaluating rotation capacity of full-restrained steel moment connections," Theoretical and Applied Mechanics 2008 Volume 35, Issue 1-3, Pages: 191-214, https://doi.org/10.2298/TAM0803191L

Lignos, D., Cravero, J., Elkady, A., (2016). "Experimental investigation of the hysteretic behavior of wide-flange steel columns under high axial load and lateral drift demands," $11^{\text {th }}$ Pacific Steel Conference, Shanghai, China, October 29-31, 2016.

McKenna, F., Fenves, G. L., Scott, M. H., and Jeremic, B., (2012). Open System for Earthquake Engineering Simulation (OpenSees). Pacific Earthquake Engineering Research Center, University of California, Berkeley, CA.

National Institute of Standards and Technology - NIST (2010). "Nonlinear Structural Analysis for Seismic Design,” NEHRP Seismic Design Technical Brief No. 4, NIST, Gaithersburg, MD.

Newell, J.D., and Uang, C. M., (2006). "Cyclic behavior of steel columns with combined high axial load and drift demand," Report No. SSRP-06/22. Department of Structural Engineering, University of California, San Diego, CA.

Pugh, J.S., Lowes, L.N., and Lehman, D.E., (2015). "Nonlinear line-element modeling of flexural reinforced concrete walls," Engineering Structures, Elsevier, 104, 174-192.

Salehi, M., and Sideris, P. (2017), "Refined Gradient Inelastic Flexibility-Based Formulation for Members Subjected to Arbitrary Loading", ASCE Journal of Engineering Mechanics, 143(9): 04017090

Scott, M.H., and Fenves, G.L., (2006). "Plastic Hinge Integration Methods for Force-Based BeamColumn Elements," Journal of Structural Engineering, 132(2), 244-252.

Scott, M.H., Franchin, P., Fenves, G.L., and Filippou, F.C., (2004). "Response Sensitivity for Nonlinear Beam-Column Elements," Journal of Structural Engineering, 130(9), 12811288. 
This peer-reviewed published paper appears as: Kolwankar, S., Kanvinde, A., Kenawy, M., Lignos, D.G., Kunnath, S. (2018). "Simulating Local Buckling-Induced Softening in Steel Members Using an Equivalent Nonlocal Material Model in Displacement-Based Fiber Elements, ASCE

Journal of Structural Engineering, Vol. 144(10): 04018192-1, doi: 10.1061/(ASCE)ST.1943-541X.0002189

Shuttle, D.A., and Smith, I.M., (1988). "Numerical simulation of shear band formation in soils," International Journal for Numerical and Analytical Methods in Geomechanics, 12, 611626.

Sideris, P., and Salehi, M., (2016). "A Gradient Inelastic Flexibility-Based Frame Element Simulation," Journal of Engineering Mechanics, ASCE, 142(7), https://doi.org/10.1061/(ASCE)EM.1943-7889.0001083

Smith, C.M., Kanvinde, A.M., and Deierlein, G.G., (2017). "A local criterion for ductile fracture under low-triaxiality axisymmetric stress states," Engineering Fracture Mechanics, Elsevier, 169, 321-335.

Spacone, E., and Filippou, F.C., (1996). "Fibre-beam column model for nonlinear analysis of R/C frames: Part I - Formulation," Earthquake Engineering and Structural Dynamics 25, 711725.

Torabian, S., and Schafer, B.W., (2014). "Role of local slenderness in the rotation capacity of structural steel members," Journal of Constructional Steel Research, 95, 32-43.

Valipour, H., and Foster, S., (2009). "Nonlocal damage formulation for a flexibility based frame element," Journal of Structural Engineering, ASCE, 135(10), 1213-1221.

Vermeer, P.A., and Brinkgreve, R.B.J., (1994). "A new effective non-local strain measure for softening plasticity," Localization and Bifurcation Theory for Soil and Rocks, Balkema, Rotterdam, 89-100.

Wu. S., and Wang, X. (2010). "Mesh dependence and nonlocal regularization of one-dimensional strain softening plasticity," Journal of Engineering Mechanics, ASCE, 136(11) 1354-1365.

Yu, C., and Schafer, B.W., (2006). "Simulation of cold-formed steel beams in local and distortional buckling with applications to the direct strength method," Journal of Constructional Steel Research, Elsevier, 63, 581-590

Zhang, G. and Khandelwal, K. (2016). "Modeling of Nonlocal Damage-Plasticity in Beams using Isogeometric Analysis." Computers \& Structures, 165, 76-95. 
This peer-reviewed published paper appears as: Kolwankar, S., Kanvinde, A., Kenawy, M., Lignos, D.G., Kunnath, S. (2018). "Simulating Local Buckling-Induced Softening in Steel Members Using an Equivalent Nonlocal Material Model in Displacement-Based Fiber Elements, ASCE

Journal of Structural Engineering, Vol. 144(10): 04018192-1, doi: 10.1061/(ASCE)ST.1943-541X.0002189

774 Table 1 - Test problems (i.e., simulation matrix) and parameters

\begin{tabular}{|l|l|l|l|l|l|l|}
\hline Test Problem & Section & $\boldsymbol{b}_{f} / 2 \boldsymbol{t}_{f}$ & $\boldsymbol{h} / \boldsymbol{t}_{\boldsymbol{w}}$ & $\boldsymbol{M} / \boldsymbol{V}(\mathbf{m m})^{\mathbf{3}}$ & $\boldsymbol{P} / \boldsymbol{P}_{\boldsymbol{y}}$ & Loading \\
\hline$\# 1-\# 3$ & $\mathrm{~W} 27 X 161$ & 6.48 & 38.55 & 4500 & $0,0.2,0.5$ & $\mathrm{NP}^{1}$ \\
\hline$\# 4-\# 6$ & $\mathrm{~W} 27 X 161$ & 6.48 & 38.55 & 2250 & $0,0.2,0.5$ & $\mathrm{NP}$ \\
\hline$\# 7-\# 8$ & $\mathrm{~W} 27 X 161$ & 6.48 & 38.55 & 4500,2250 & 0.5 & $\mathrm{P}^{2}$ \\
\hline$\# 9-\# 11$ & $\mathrm{~W} 27 X 84$ & 7.81 & 55.26 & 4500 & $0,0.2,0.5$ & $\mathrm{NP}$ \\
\hline$\# 12-\# 14$ & $\mathrm{~W} 27 X 84$ & 7.81 & 55.26 & 2250 & $0,0.2,0.5$ & $\mathrm{NP}$ \\
\hline$\# 15-\# 16$ & $\mathrm{~W} 27 X 84$ & 7.81 & 55.26 & 4500,2250 & 0.5 & $\mathrm{P}$ \\
\hline$\# 17-\# 19$ & $\mathrm{~W} 24 X 146$ & 5.92 & 34.65 & 4500 & $0,0.2,0.5$ & $\mathrm{NP}$ \\
\hline$\# 20-\# 22$ & $\mathrm{~W} 24 X 146$ & 5.92 & 34.65 & 2250 & $0,0.2,0.5$ & $\mathrm{NP}$ \\
\hline$\# 23-\# 24$ & $\mathrm{~W} 24 X 146$ & 5.92 & 34.65 & 4500,2250 & 0.5 & $\mathrm{P}$ \\
\hline$\# 25-\# 27$ & $\mathrm{~W} 24 X 68$ & 7.67 & 54.29 & 4500 & $0,0.2,0.5$ & $\mathrm{NP}$ \\
\hline$\# 28-\# 30$ & $\mathrm{~W} 24 X 68$ & 7.67 & 54.29 & 2250 & $0,0.2,0.5$ & $\mathrm{NP}$ \\
\hline$\# 31-\# 32$ & $\mathrm{~W} 24 X 68$ & 7.67 & 54.29 & 4500,2250 & 0.5 & $\mathrm{P}$ \\
\hline$\# 33-\# 35$ & $\mathrm{~W} 21 X 48$ & 9.47 & 56.40 & 4500 & $0,0.2,0.5$ & $\mathrm{NP}$ \\
\hline$\# 36-\# 38$ & $\mathrm{~W} 21 X 48$ & 9.47 & 56.40 & 2250 & $0,0.2,0.5$ & $\mathrm{NP}$ \\
\hline$\# 39-\# 40$ & $\mathrm{~W} 21 X 48$ & 9.47 & 56.40 & 4500,2250 & 0.5 & $\mathrm{P}$ \\
\hline$\# 41-\# 43$ & $\mathrm{~W} 16 X 89^{4}$ & 5.94 & 28.67 & 1875 & $0,0.3,0.5$ & $\mathrm{NP}$ \\
\hline
\end{tabular}

775

776

777

778

779

780

781

782

783

784

785

786

787

788

789

790

9

80

86

${ }^{1,2}$ Non-Proportional and Proportional loading

${ }^{3} \mathrm{M} / \mathrm{V}$ represents the moment gradient also equal to length of cantilever model

${ }^{4}$ Complementary to experiments by Lignos et al., (2016)

1

2

33

4

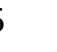


This peer-reviewed published paper appears as: Kolwankar, S., Kanvinde, A., Kenawy, M., Lignos, D.G., Kunnath, S. (2018). "Simulating Local Buckling-Induced Softening in Steel Members Using an Equivalent Nonlocal Material Model in Displacement-Based Fiber Elements, ASCE Journal of Structural Engineering, Vol. 144(10): 04018192-1, doi: 10.1061/(ASCE)ST.1943-541X.0002189

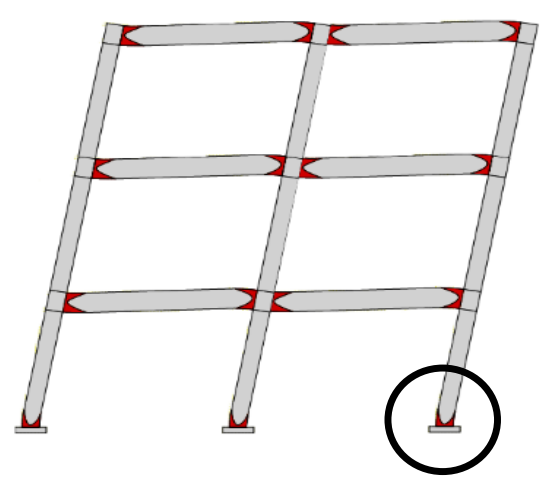

Plastic hinge with local buckling

799

800

801

802

803

804

805

806

807

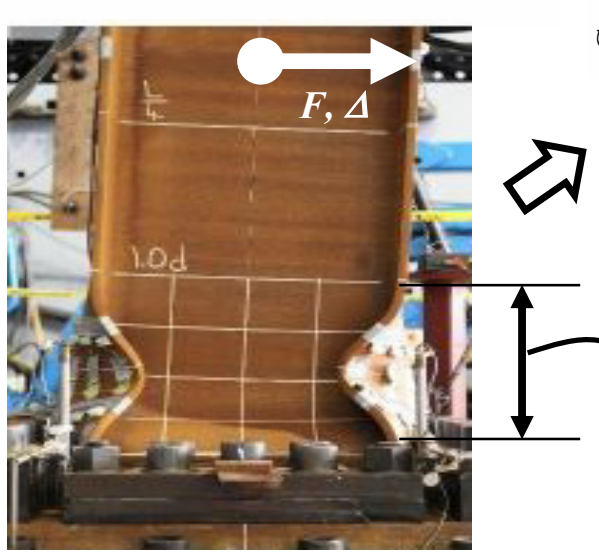

Figure 1 - The problem and causes of mesh dependence in rolled steel members with local buckling

Mesh discretization that disregards physical length scale

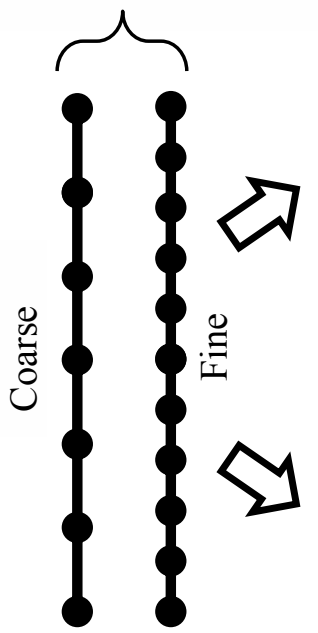

Physical length

scale associated with local buckling

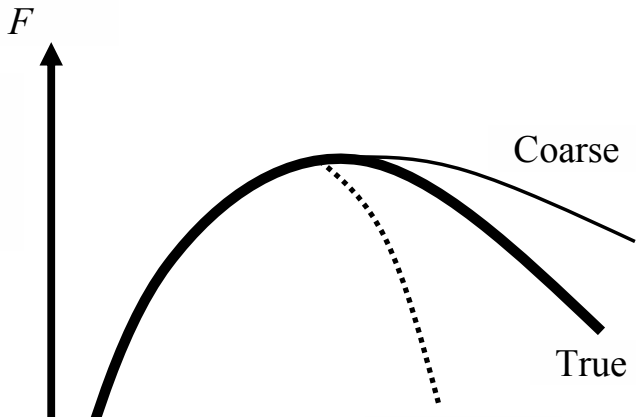

Fine

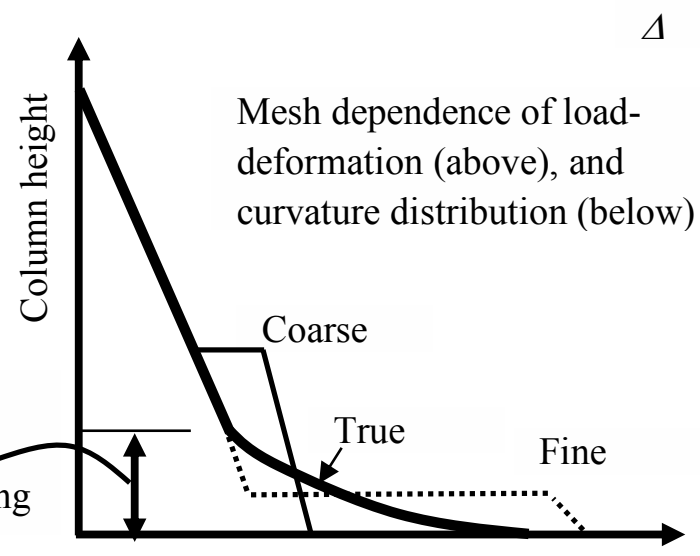

Curvature 
This peer-reviewed published paper appears as: Kolwankar, S., Kanvinde, A., Kenawy, M., Lignos, D.G., Kunnath, S. (2018). "Simulating Local Buckling-Induced Softening in Steel Members Using an Equivalent Nonlocal Material Model in Displacement-Based Fiber Elements, ASCE Journal of Structural Engineering, Vol. 144(10): 04018192-1, doi: 10.1061/(ASCE)ST.1943-541X.0002189

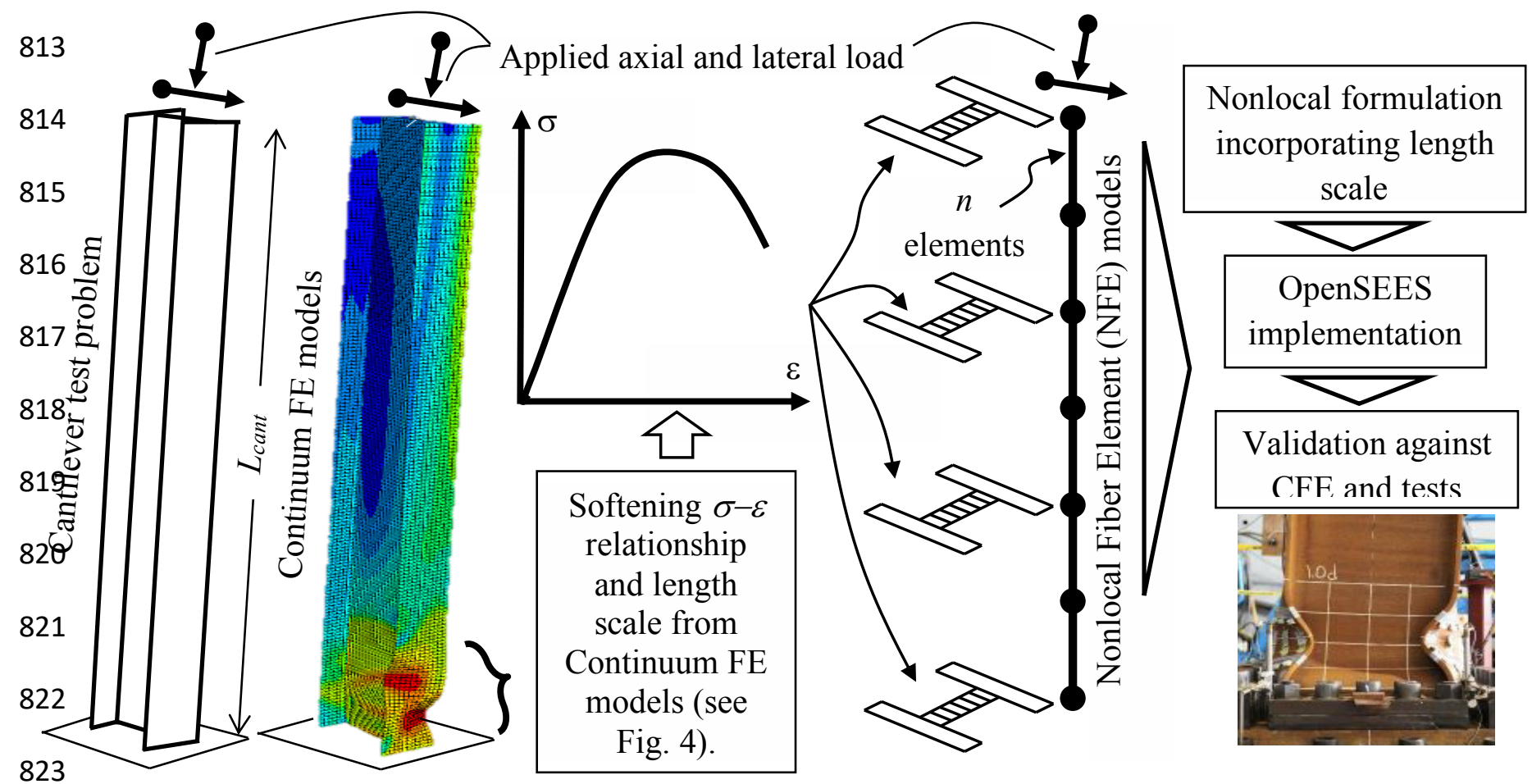


This peer-reviewed published paper appears as: Kolwankar, S., Kanvinde, A., Kenawy, M., Lignos, D.G., Kunnath, S. (2018). "Simulating Local Buckling-Induced Softening in Steel Members Using an Equivalent Nonlocal Material Model in Displacement-Based Fiber Elements, ASCE Journal of Structural Engineering, Vol. 144(10): 04018192-1, doi: 10.1061/(ASCE)ST.1943-541X.0002189

828

829

830

831

832

833

834

835

836

837

838

839

840

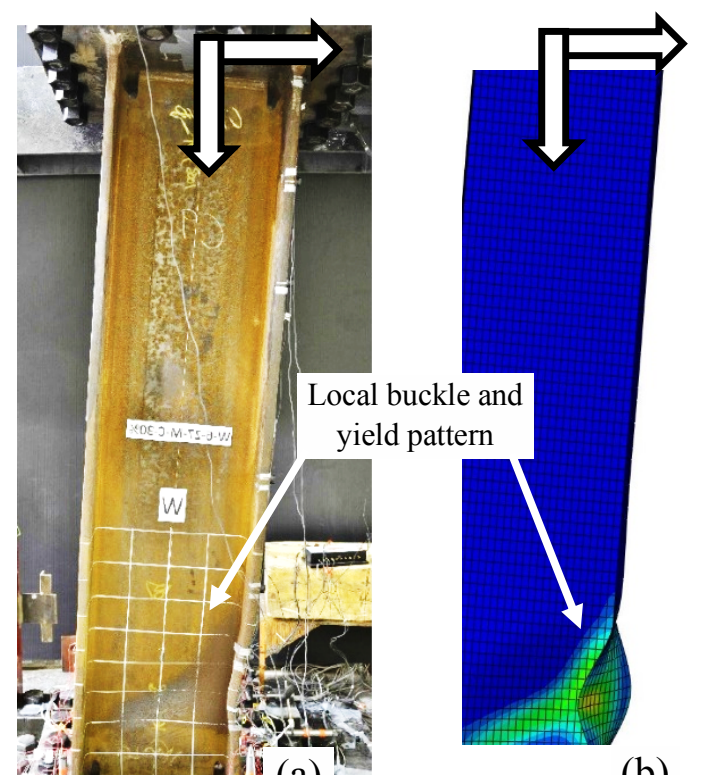

(b)

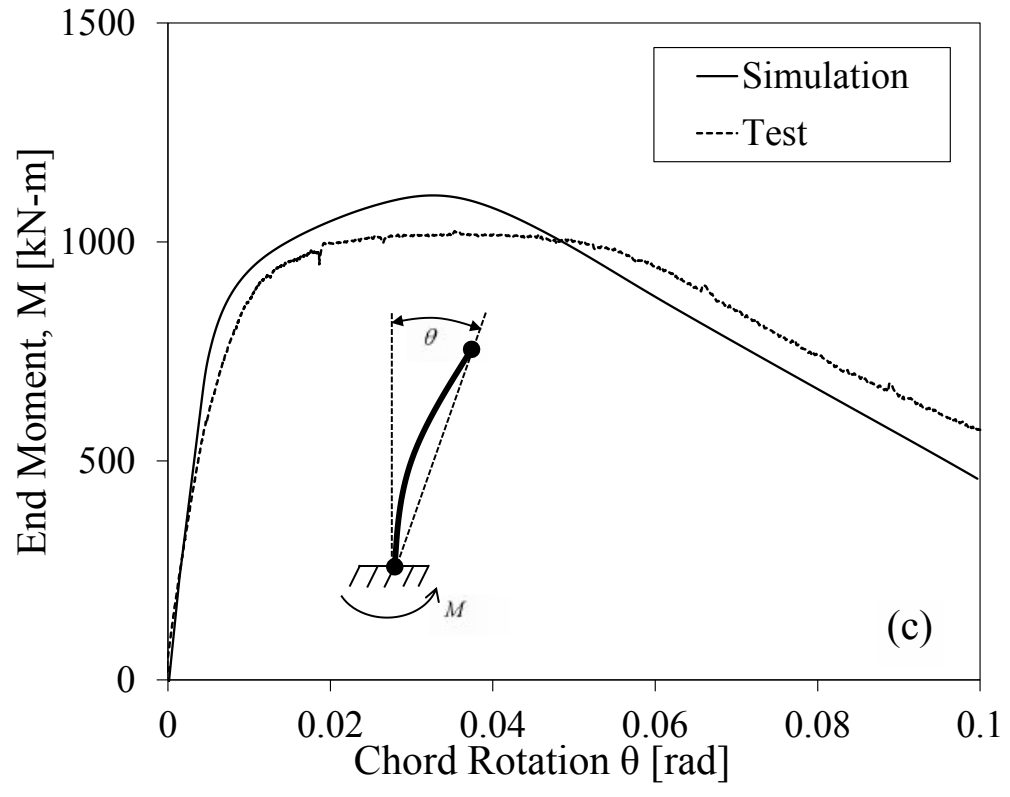

Figure 3 - Representative comparison between results from experiments (W16X89, $P / P_{y}=0.3$ ) and Continuum Finite Element (CFE) simulations (a) test specimen post local buckling at 8\% chord rotation (b) simulation at at $8 \%$ chord rotation (c) load-deformation curve 
(a)

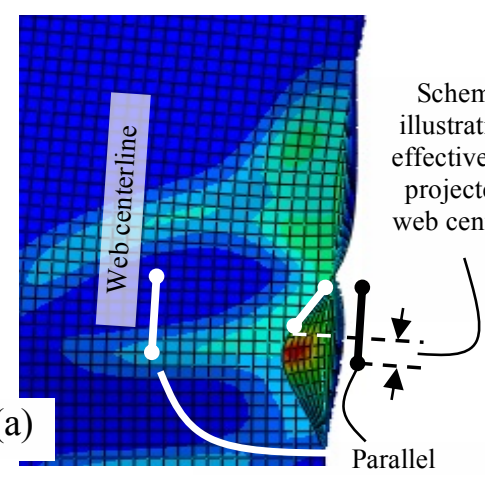

852

853

854

855

856

857

858

859
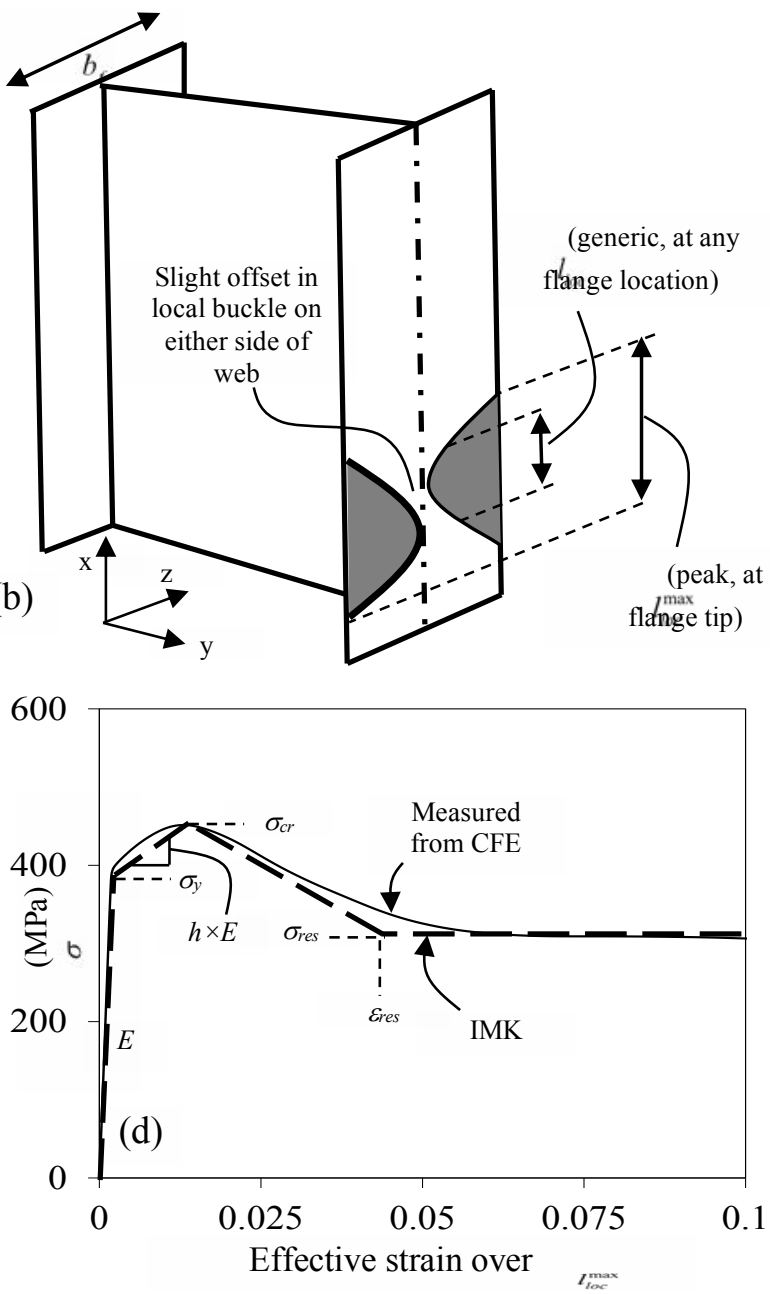

Figure 4 - Quantities derived from CFE simulations (a) effective or projected strain, (b) spatial distribution 860 of localization length at an arbitrary time instant post-localization, (c) temporal evolution of flange tip

861 (peak) localized length axd (d) effective stress-strain relationship measured over approximationcthrough IMK model (only compression quadrant shown) $l_{l o c}^{\max }$ 


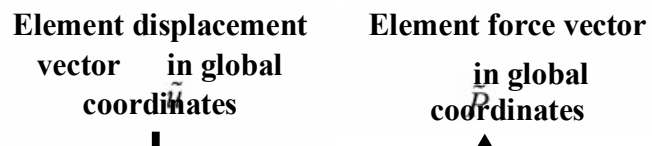

coordi花ates coớrinates
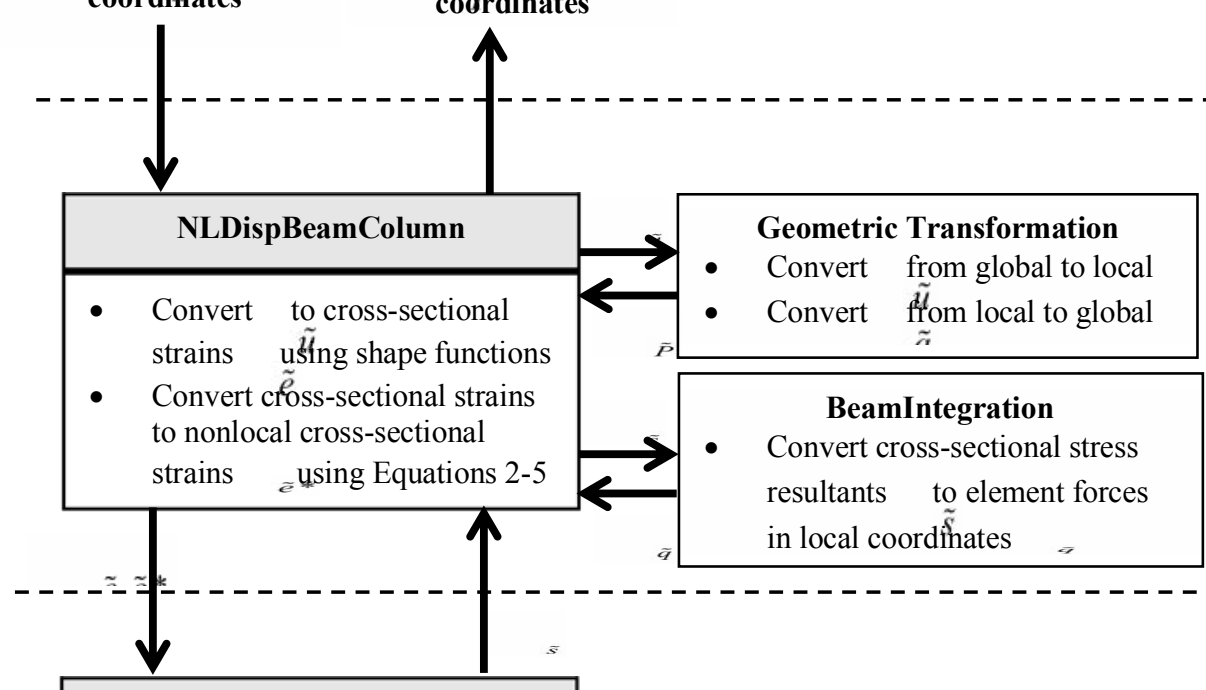

Geometric Transformation

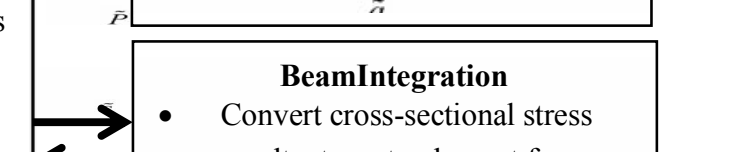
resultants to element forces in local coordiñates
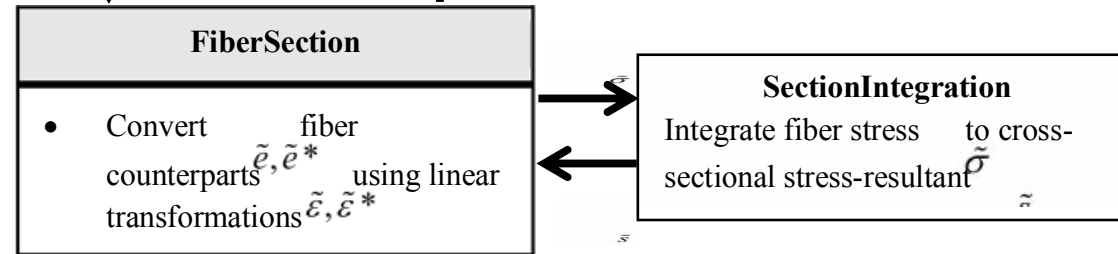

$\underset{0}{0}$

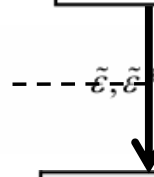

$$
\text { ( }
$$

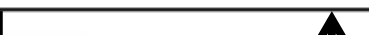

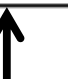
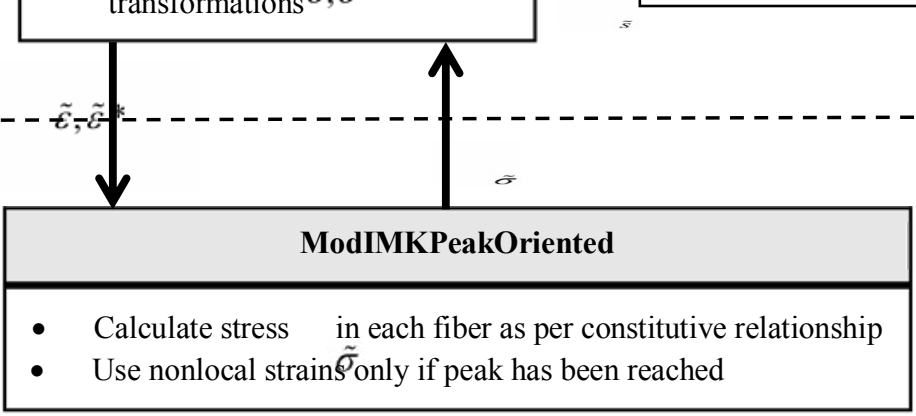

Figure 5 - Algorithmic implementation in OpenSEES; shaded boxes indicate modified objects or classes 
This peer-reviewed published paper appears as: Kolwankar, S., Kanvinde, A., Kenawy, M., Lignos, D.G., Kunnath, S. (2018). "Simulating Local Buckling-Induced Softening in Steel Members Using an Equivalent Nonlocal Material Model in Displacement-Based Fiber Elements, ASCE Journal of Structural Engineering, Vol. 144(10): 04018192-1, doi: 10.1061/(ASCE)ST.1943-541X.0002189
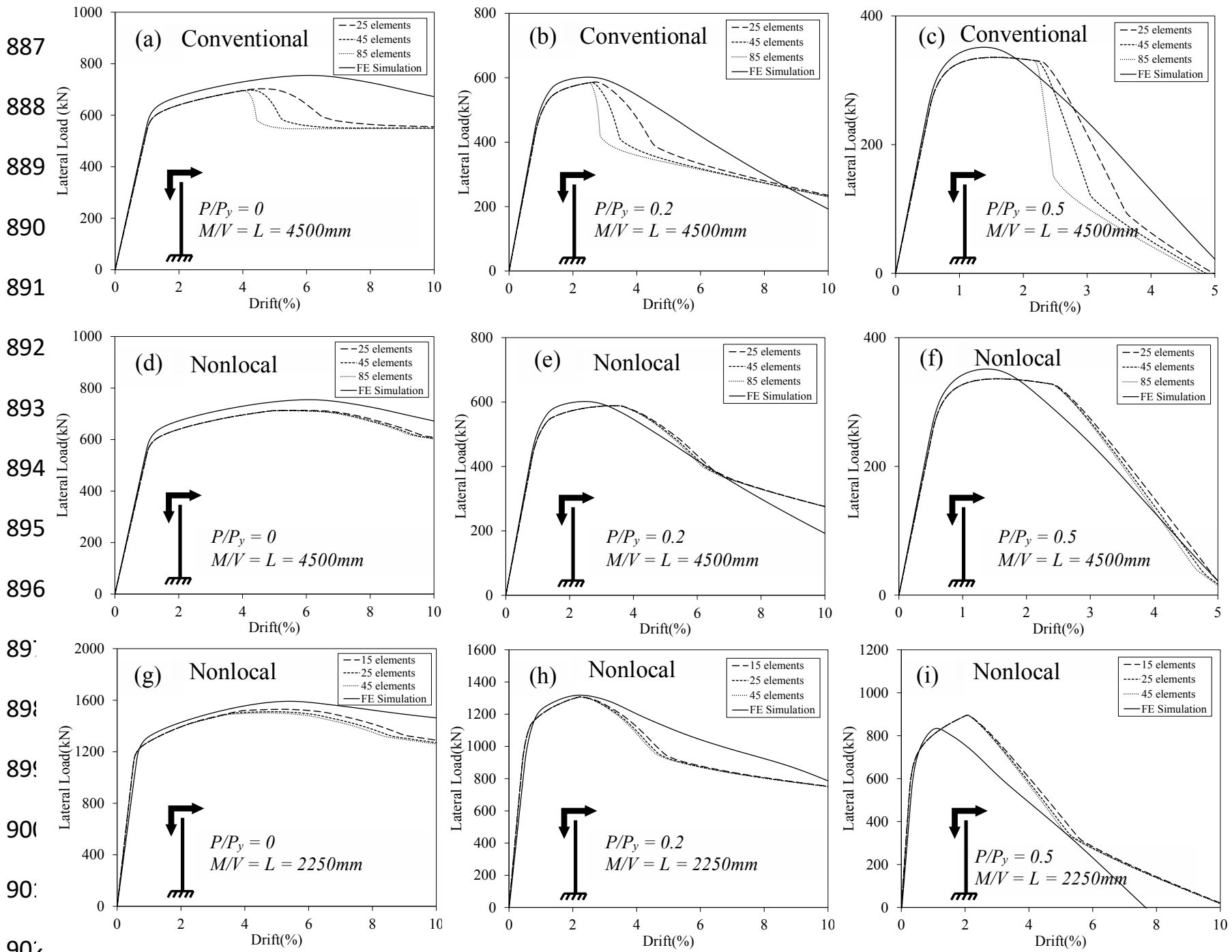

Figure 6 - Representative load-displacement curves from select test problems with W24X146: (a)-(c) traditional fiber approach, (d)-(i) NFE approach 
This peer-reviewed published paper appears as: Kolwankar, S., Kanvinde, A., Kenawy, M., Lignos, D.G., Kunnath, S. (2018). "Simulating Local Buckling-Induced Softening in Steel Members Using an Equivalent Nonlocal Material Model in Displacement-Based Fiber Elements, ASCE Journal of Structural Engineering, Vol. 144(10): 04018192-1, doi: 10.1061/(ASCE)ST.1943-541X.0002189
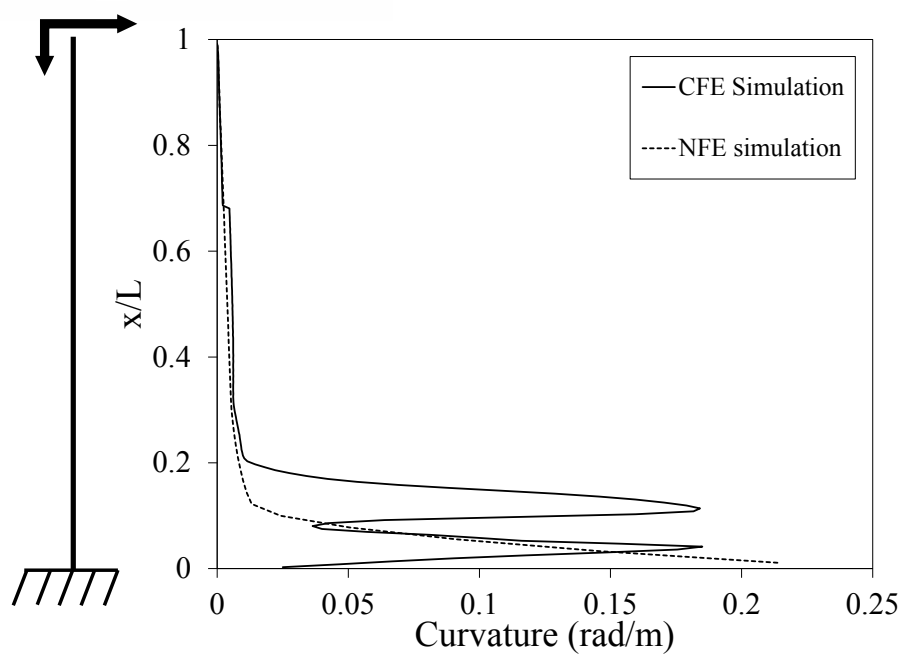

Figure 7 - Post localization curvature profile for 
This peer-reviewed published paper appears as: Kolwankar, S., Kanvinde, A., Kenawy, M., Lignos, D.G., Kunnath, S. (2018). "Simulating Local Buckling-Induced Softening in Steel Members Using an Equivalent Nonlocal Material Model in Displacement-Based Fiber Elements, ASCE Journal of Structural Engineering, Vol. 144(10): 04018192-1, doi: 10.1061/(ASCE)ST.1943-541X.0002189
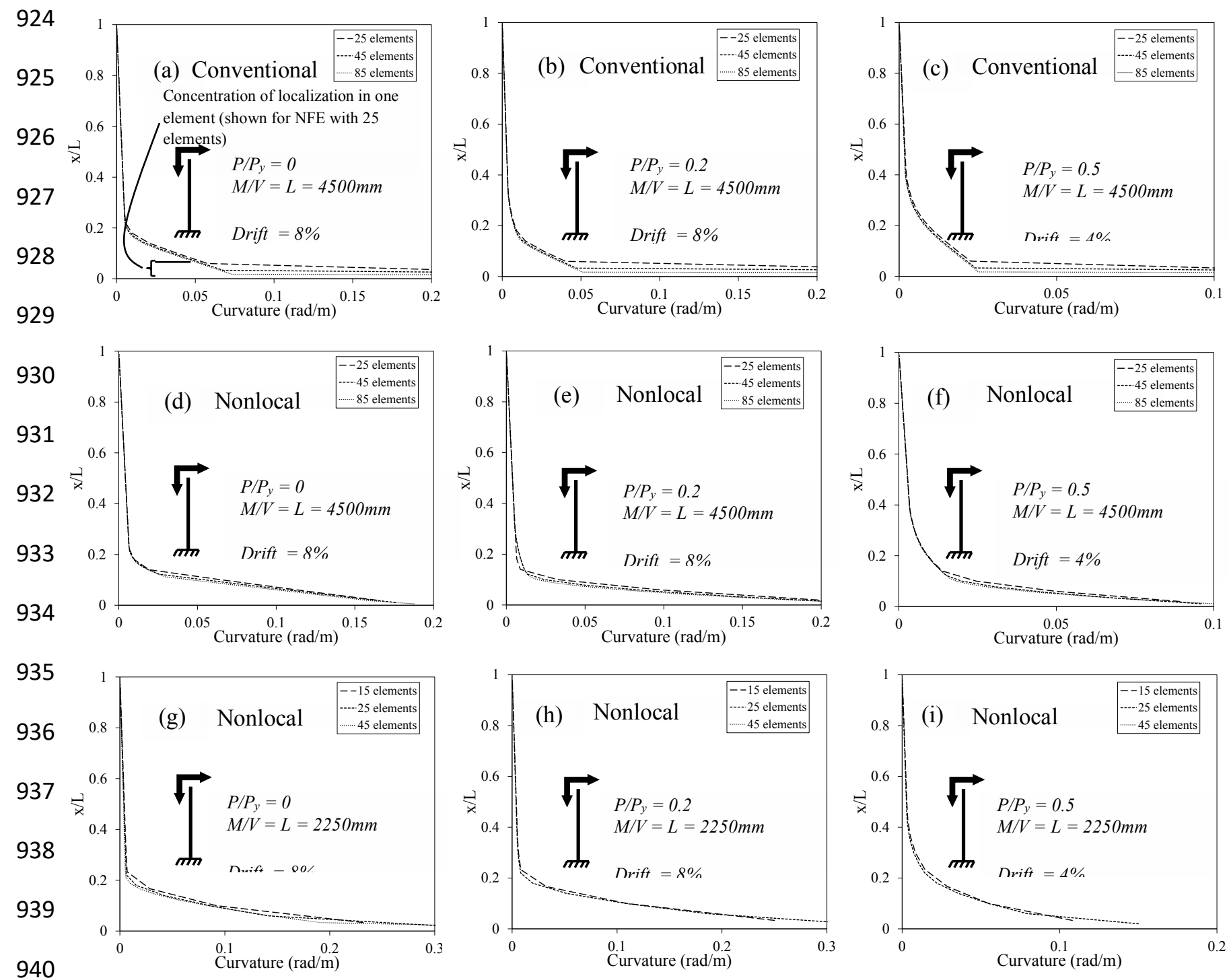

Figure 8 - Representative curvature distribution from select test problems with 
This peer-reviewed published paper appears as: Kolwankar, S., Kanvinde, A., Kenawy, M., Lignos, D.G., Kunnath, S. (2018). "Simulating Local Buckling-Induced Softening in Steel Members Using an Equivalent Nonlocal Material Model in Displacement-Based Fiber Elements, ASCE Journal of Structural Engineering, Vol. 144(10): 04018192-1, doi: 10.1061/(ASCE)ST.1943-541X.0002189
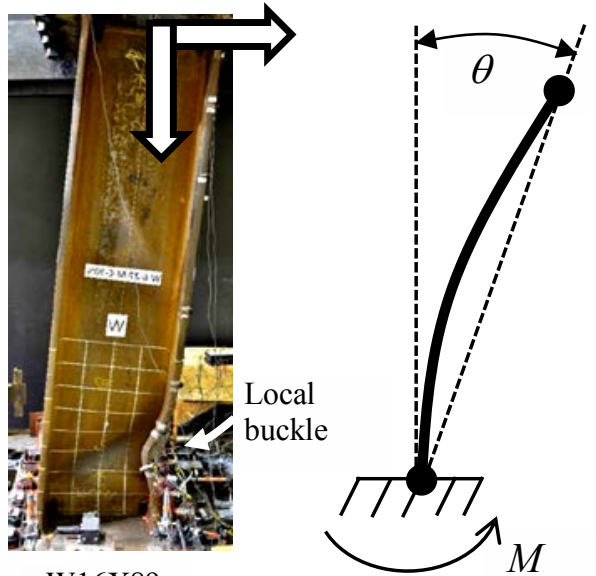

950

W16X89
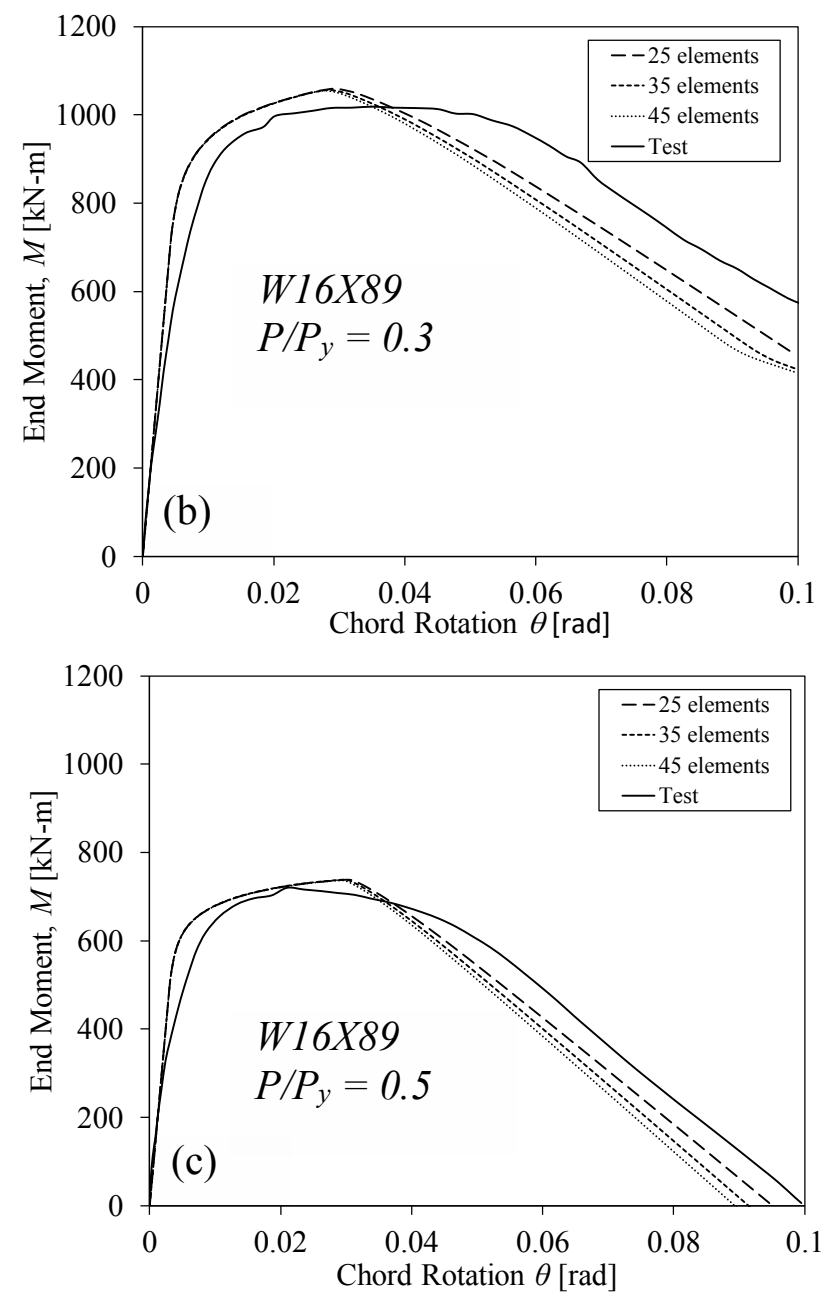

965

Figure 9 - Prediction of tests results by Lignos et al., (2016): (a) Test photograph and illustration of plotted quantities, (b) results from test and NFE model for W16X89, with $P / P_{y}=0.3$ and (c) for $P / P_{y}=0.5$ 